Article

\title{
Proteomic Investigations of Two Pakistani Naja Snake Venoms Species Unravel the Venom Complexity, Posttranslational Modifications, and Presence of Extracellular Vesicles
}

\author{
Aisha Manuwar ${ }^{1, *}$, Benjamin Dreyer ${ }^{2}{ }^{(1)}$, Andreas Böhmert ${ }^{2}$, Anwar Ullah ${ }^{3}{ }^{(\mathbb{D}}$, Zia Mughal $^{4}$, \\ Ahmed Akrem ${ }^{5}$, Syed Abid Ali ${ }^{6}\left(\mathbb{D}\right.$, Hartmut Schlüter ${ }^{2}\left(\mathbb{D}\right.$ and Christian Betzel ${ }^{7} *$ \\ 1 Department of Chemistry, University of Engineering and Technology, Lahore 54890, Pakistan \\ 2 Institute of Clinical Chemistry and Laboratory Medicine, Mass Spectrometric Proteomics, \\ University Medical Centre Hamburg-Eppendorf (UKE), Martinistraße 52, 20246 Hamburg, Germany; \\ b.dreyer@uke.de (B.D.); andy.boehmert@googlemail.com (A.B.); hschluet@uke.de (H.S.) \\ 3 Department of Biosciences, COMSATS University Islamabad, Park Road, Chack Shahzad, \\ Islamabad 45550, Pakistan; anwar.ms90@yahoo.com \\ 4 Pet Centre, University of Veterinary and Animal Sciences, Lahore 54890, Pakistan; zia_mgl@hotmail.com \\ 5 Botany Division, Institute of Pure and Applied Biology, Bahauddin Zakariya University, \\ Multan 60800, Pakistan; ahmedakrem@bzu.edu.pk \\ 6 Husein Ebrahim Jamal Research Institute of Chemistry, (International Center for Chemical and Biological \\ Sciences), University of Karachi, Karachi 75270, Pakistan; abid.ali@iccs.edu \\ 7 Laboratory for Structural Biology of Infection and Inflammation, Institute of Biochemistry and Molecular \\ Biology, Deutsches Elektronen-Synchrotron, Build. 22a, Notkestr. 85, University of Hamburg, \\ 22603 Hamburg, Germany \\ * Correspondence: aisha.munawar@uet.edu.pk (A.M.); christian.betzel@uni-hamburg.de (C.B.)
}

Received: 13 September 2020; Accepted: 20 October 2020; Published: 22 October 2020

\begin{abstract}
Latest advancement of omics technologies allows in-depth characterization of venom compositions. In the present work we present a proteomic study of two snake venoms of the genus Naja i.e., Naja naja (black cobra) and Naja oxiana (brown cobra) of Pakistani origin. The present study has shown that these snake venoms consist of a highly diversified proteome. Furthermore, the data also revealed variation among closely related species. High throughput mass spectrometric analysis of the venom proteome allowed to identify for the N. naja venom 34 protein families and for the $N$. oxiana 24 protein families. The comparative evaluation of the two venoms showed that N. naja consists of a more complex venom proteome than N. oxiana venom. Analysis also showed $\mathrm{N}$-terminal acetylation ( $\mathrm{N}$-ace) of a few proteins in both venoms. To the best of our knowledge, this is the first study revealing this posttranslational modification in snake venom. $\mathrm{N}$-ace can shed light on the mechanism of regulation of venom proteins inside the venom gland. Furthermore, our data showed the presence of other body proteins, e.g., ankyrin repeats, leucine repeats, zinc finger, cobra serum albumin, transferrin, insulin, deoxyribonuclease-2-alpha, and other regulatory proteins in these venoms. Interestingly, our data identified Ras-GTpase type of proteins, which indicate the presence of extracellular vesicles in the venom. The data can support the production of distinct and specific anti-venoms and also allow a better understanding of the envenomation and mechanism of distribution of toxins. Data are available via ProteomeXchange with identifier PXD018726.
\end{abstract}

Keywords: Naja naja; Naja oxiana; venom proteome; Ras-GTPase; ankyrin repeat; N-terminal acetylation; extracellular vesicles 
Key Contribution: The present study describes a comprehensive overview of the venom proteome of Naja naja and Naja oxiana. A few protein fragments were found to be N-terminal acetylated. The identification of Ras-like proteins in the venom of Naja naja indicates the presence of extracellular vesicles in the venom.

\section{Introduction}

Pakistan has a particular geographical location and hosts an array of habitats such a, mountains, glaciers, coastal areas, swamps, plane areas, fresh water, and sandy areas [1]. The country is located between two zoogeographical regions (Palearctic and Oriental) and hosts a diverse venomous fauna. Nine habitat zones are recognized according to the distribution of snakes in Pakistan [2]. Seventy-two snake species are known to Pakistan, among which 14 marine and 12 terrestrial are venomous [1]. According to ITIS (Integrated Taxonomic Information System) database there are 29 snake species belonging to the genus Naja [3]. Among these two are found in Pakistan, i.e., Naja naja and Naja oxiana [2]. Both of these snakes are non-spitting cobras [4]. These snakes are shy of humans. However, upon assessing threat they lift the anterior part of their body, display a hood, and if provoked, hiss loudly and sway their hood to frighten their adversary. These snakes attack very furiously, chewing the bitten part. They usually feed on rodents, birds, frogs, lizards, and snakes. They are found in rocky, stony foothills, forests and around the villages [2]. N. naja (black cobra) is known to have variable color and pattern. However, in Pakistan juveniles and young adults tend to be grey with hood marks, but the adult specimens are usually uniformly black. In addition, the throat pattern is obscured in adult snakes, due to pigmentation [4,5]. N. naja is distributed in North West Pakistan, south and desert areas, except most of Baluchistan. N. oxiana (brown cobra) occurs sympatrically in the Northern half of Pakistan with N. naja. Adult N. oxiana is normally brown in color [5,6]. These snakes and their geographical distribution are shown in Figure 1.
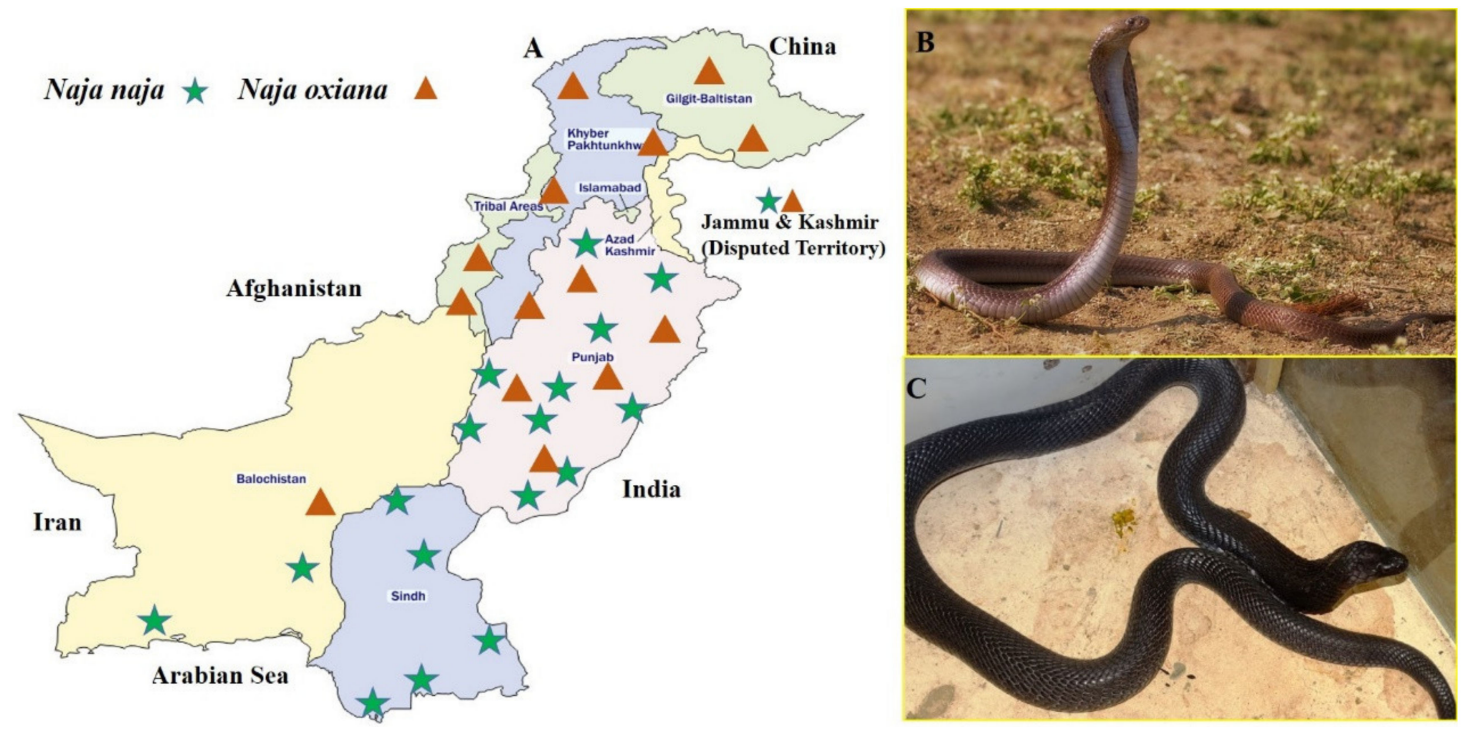

Figure 1. (A) Geographical distribution of the genus Naja snakes in Pakistan. (B) Naja oxiana (Brown cobra) (C) Naja naja (black cobra).

Only a few reliable data exist reporting the frequency of morbidity because of snakebites in developing countries. However, it is predicted that snakebite is responsible for a substantial amount of morbidity and mortality in remote areas [7]. The hidden toll of suffering continues to affect the families of the deceased, and patients who survived with crippling deformity [8]. World Health Organization (WHO), included snakebite in its list of "Neglected Tropical disease" in 2007 [9]. Recently, WHO also 
added snakebite envenoming at high preference in the list of Neglected Tropical disease, in 2017, upon request of some member states of United Nations. The supply of antivenom and snakebite management was declared as a global public health emergency. WHO has included snake antivenom immunoglobulins in the "WHO Model List for Essential Medicines" WHO has also encouraged countries to ensure their national antivenom stocks [10] Despite these efforts, snakebite has not gained attention on international public health agendas [11]. The snakes commonly responsible for clinically significant bites in Pakistan are Bungarus caeruleus (common krait), N. naja (cobra), Daboia russelii (Russel's viper), and Echis carinatus (Saw-scaled viper) [12]. National Institute of Health, Pakistan, produces around 30,000 vials of polyvalent anti-venom per year. However, the amount of this antivenom is not sufficient and can only treat a fraction of snakebite cases in the country (https://www.nih.org.pk/1255-2/) [13]. To meet the requirement of antivenoms, snake antivenom sera are presently also imported from India. However, studies have shown that Indian antivenoms provide partial neutralization, particularly for N. naja venom [14-16]. Although, N. naja and N. oxiana are also prevalent in India, but the venom composition is known to vary within the same species, due to change in geographical and ecological factors [17-20]. A study reported that Pakistani N. naja is more neurotoxic with lower $\mathrm{LD}_{50}$, then that prevalent in India [8]. Gender, diet, and age of the snake is also known to influence the composition of venoms [21-24].

Depending on the amount of venom injected, paralysis following cobra bites can occur within several hours, with death ensuing if breathing is not assisted [8]. On average cobras can inject $60 \mathrm{mg}$ of venom in a bite [25]. Cobra venom is a postsynaptic neurotoxin and presents a variety of symptoms like pain, edema, necrosis, respiratory paralysis, headache, cardiac arrest, hypotension, and bleeding wounds [26]. The use of anticholinesterase, such as neostigmine, has been suggested to compensate a cobra bite, in addition to the administration of antivenom $[25,26]$.

Recent scientific advances have paved the way to explore venomous snake composition in detail and various strategies have been evolved to better understand venom components, their function and immunological properties [27]. Genomic and transcriptomic studies have proved to be an invaluable tool in the discovery of the snake venom evolution and proteoform [28-34]. Consequently, investigations are directed towards the discovery of pharmacologically active snake venom compounds [35-38]. For example, a recent study reported Mambaquaretin-1 (peptide from green mamba venom), as a promising candidate for the treatment of polycystic kidney disease [39]. Another study described Nubein6.8, a peptide from the venom of $N$. nubiae, as a promising template for the treatment of human melanoma and ovarian cancer [40].

In the present study, we describe an in-depth comparative proteomic study of two Pakistani snake species of the family elapid and genus Naja, i.e., N. oxiana (brown cobra/Caspian cobra/Central Asian cobra) and N. naja (black cobra/Indian cobra/Spectacled cobra). In Pakistani region both species of adult cobras are melatonic and N. oxiana is commonly known as brown, while N. naja is known as black cobra. These snakes were previously known as Naja n. oxiana and Naja $n$. karachienis respectively, but now they are named according to the ITIS database [41]. Till now only a few studies have been reported about the proteomics of Pakistani N. naja [42-44]. The N. naja venom samples in these studies were collected from Southern Punjab and Sindh Province of Pakistan. These research groups performed pre fractionation of the venom sample either by reverse phase chromatography, 1-dimensional gel electrophoresis (1D gel) or 2-dimensional gel electrophoresis (2 D gel) or a combination of these methods. Further mass spectrometric analysis of peptide fragments obtained from in gel trypsin digestion, was carried out by MALDI TOF/TOF, ion trap or ESI MS. Chanda et al. also reported the venom proteomics of $N$. naja, from Western and Eastern parts of India $[45,46]$. In their study of the venom sample from East India, they pre fractionated the crude venom by 1D gel prior to LTQ orbitrap analysis. However, the proteomic analysis of the venom sample from Western India was performed by a combination of fractionation methods and LC-MS/MS was done by QTOF mass spectrometer. Analysis of the comparative statement of the research group showed that pre fractionation of the crude 
venom by gel filtration chromatography followed by gel electrophoresis, worked best in their hands. The same group reported the proteomic study of South Indian N. naja venom, recently [47].

In this work, they separated the crude venom components by $1 \mathrm{D}$ gel electrophoresis. The mass spectrometric analysis of the tryptic peptide was performed on QTOF. The results of this study derive a comparison of common and unique toxins in N. naja venom obtained from all the three different Indian regions. Our results revealed remarkable differences in the relative abundance of the venom components, as compared to the previous studies. In addition, our investigations unveiled new venom components, not reported before in these venoms. The variation in the results could be different geographical of the snakes from which we collected the venom samples. Further, our workflow did not involve any pre fractionation of the venom. Pre fractionation by gel electrophoresis or liquid chromatography might lead to the loss of some low abundant venom components. Also, we used a modern version of the orbitrap mass spectrometer in this work which is very sensitive equipment.

To the best of our knowledge, this is the first report on the proteomic study of Naja oxiana venom. The abbreviations used for proteins and peptides are given in Table 1.

Table 1. Comparative evaluation of snake venom protein families in the venom of N. naja and N. oxiana.

\begin{tabular}{|c|c|c|c|c|c|c|}
\hline Protein Family & $\begin{array}{l}\text { First Report in } \\
\text { Nn Venom }\end{array}$ & $\begin{array}{l}\text { Abbreviation } \\
\text { Used }\end{array}$ & $\begin{array}{l}\text { NN (No } \\
\text { of Peptides) }\end{array}$ & $\%$ Age & $\begin{array}{l}\text { NO(No. } \\
\text { of Peptides) }\end{array}$ & $\%$ Age \\
\hline Three-Finger toxin & & 3FTX & 157 & 21 & 41 & 16 \\
\hline Cobra venom factor & & CVF & 62 & 9 & 22 & 8.7 \\
\hline Cysteine-rich secretory protein & & CRISP & 53 & 7 & 7 & 2.8 \\
\hline Phospholipase A2 & & PLA2 & 46 & 6 & 32 & 12.6 \\
\hline L-amino-acid oxidase & & LAAO & 31 & 4 & 14 & 5.5 \\
\hline Snake Venom Serine proteinase & & SP & 15 & 2 & 11 & 4.3 \\
\hline Ohanin & & $\mathrm{Oh}$ & 11 & 1.5 & 2 & 0.8 \\
\hline Kunitz type serine protease inhibitor & & KSPI & 14 & 2 & 4 & 1.6 \\
\hline Nerve Growth Factor & & NGF & 12 & 1.7 & 11 & 4.3 \\
\hline $5^{\prime}$-nucleotidase & & $5-\mathrm{Ntd}$ & 10 & 1.4 & 1 & 0.4 \\
\hline Aminopeptidase & & - & 7 & 1 & 4 & 1.6 \\
\hline TNF receptor family & $\checkmark$ & TNF & 2 & 0.3 & 3 & 1.2 \\
\hline Lectin & $\checkmark$ & - & 3 & 0.4 & 1 & 0.4 \\
\hline Natriuretic peptide family & & NP & 4 & 0.54 & 1 & 0.4 \\
\hline Cystatin & & - & 4 & 0.54 & - & \\
\hline Cathelicidin & $\checkmark$ & cath & 1 & 0.1 & - & \\
\hline N-acetylcholinesterase & & N-Ache & 1 & 0.1 & 1 & 0.4 \\
\hline Vascular endothelial growth factor & & VEGF & 1 & 0.1 & - & \\
\hline Transforming growth factor & $\checkmark$ & TGF & 2 & 0.3 & - & \\
\hline Zinc finger protein & $\checkmark$ & ZFP & 6 & 0.8 & 4 & 1.6 \\
\hline Insulin & $\checkmark$ & In & 2 & 0.3 & - & \\
\hline Transferrin & $\checkmark$ & $\mathrm{TF}$ & 2 & 0.3 & - & \\
\hline Total & & & 735 & & 254 & \\
\hline
\end{tabular}

Bold text in the first column indicates protein families exclusively identified in N. naja venom. Blue coloured text indicates protein family identified only in N. oxiana. Check mark $(\checkmark)$ in the second column, indicates that this work is the first report of the identification of the corresponding protein families in N.naja venom. The dash sign indicate that the protein family was not identified in the venom.

\section{Results}

The venom proteome of $N$. naja $(\mathrm{NN})$ and $N$. oxiana $(\mathrm{NO})$ snakes was investigated by mass spectrometric analysis, using a shotgun proteomic approach. We were able to provide an extensive 
overview of various protein families present in both venoms, based on data base searches and BLAST analysis of the de novo sequenced tandem mass spectra. A total of 735 peptides from NN and 254 peptides from NO were sequenced (Supplementary Table S1 and S2). Subsequently 365 proteins in NN venom (Table 2) and 140 proteins were identified in NO venom (Table 3). The sequences of the protein fragments are listed in Supplementary Tables S1 and S2. The results obtained allowed us to cluster the venom protein content into 34 protein families for $N$. naja and in 24 protein families for the N. oxiana venom. Figure 2A illustrates the preparation for MS acquisition and Figure $2 \mathrm{~B}$ represents the strategy applied for data base searches. In the present work, we performed data base search against Serpents, King cobra utilizing Uniprot data base. The venom of Ophiophagus hannah has been well studied and genomic and proteomic data are available in the database [28,48,49]. A recent study showed similarity between the genome of Indian cobra and King cobra [50]. This group analyzed 139 N. naja venom gland toxin genes to identify orthologs in the King cobra. It was determined that 96 genes matched while 43 did not. It was suggested that, although some genes are likely to be unique to Indian cobra, the majority were not annotated in King cobra genome. The possible reason could be its highly fragment assembly. Based on this similarity, we searched our data against King cobra database also. Further, in the data base complete proteome of only King cobra is available. The details of our search against Serpent database are presented in Supplementary Table S3 and S5 while that against King cobra are compiled in Supplementary Table S4 and S6. The results presented and discussed are a conclusion of both data base searches.

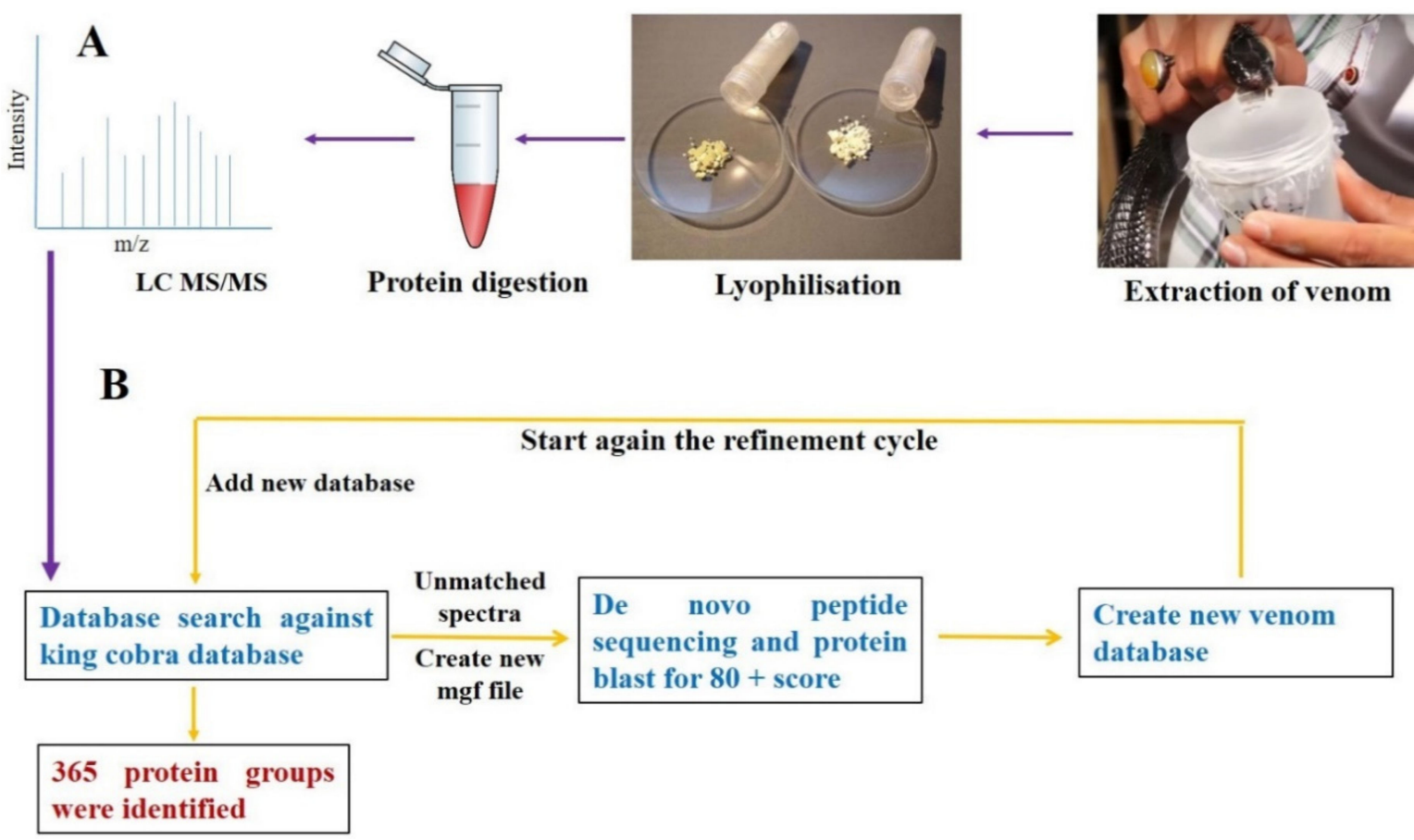

Figure 2. (A) Milking of N. naja venom and sample preparation for LC-MS/MS analysis (B) Data base search cycle. 
Table 2. Summary of the venom proteome of Naja naja.

\begin{tabular}{|c|c|c|c|c|c|}
\hline S. No & Protein Family & Protein & Accession Code & $\begin{array}{l}\text { Number of } \\
\text { Matched Peptides }\end{array}$ & $\begin{array}{l}\text { Homology with a Protein from } \\
\text { the Venom of Snake Species }\end{array}$ \\
\hline 1 & 3FTXs (Neurotoxin) & Long neurotoxin & AHZ08824 & 9 & Micropechis ikaheca \\
\hline 2 & & & P01389 & 1 & Naja anchietae \\
\hline 3 & & & P01390 & 2 & Naja nivea \\
\hline 4 & & Long neurotoxin homolog & O93422 & 5 & Naja atra \\
\hline 5 & & Long neurotoxin 1 & P25668 & 4 & Naja naja \\
\hline 6 & & Long neurotoxin 1 & P01380 & 1 & Hydrophis stokesii \\
\hline 7 & & Long neurotoxin 1 & P25674 & 3 & Naja haje haje \\
\hline 8 & & Long neurotoxin 4 & P25672 & 3 & Naja naja \\
\hline 9 & & Long neurotoxin 7 & $\mathrm{O} 42257$ & 3 & Naja sputatrix \\
\hline 10 & & putative long neurotoxin & ABX58151 & 1 & Austrelaps labialis \\
\hline 11 & & putative long neurotoxin & ABX58163 & 1 & Austrelaps labialis \\
\hline 12 & & Alpha-neurotoxin NTX-3 & O57326 & 1 & Naja sputatrix \\
\hline 13 & & Short neurotoxin 3 & P01420 & 1 & Naja annulifera \\
\hline 14 & & Short neurotoxin III & P59275 & 1 & Naja kaouthia \\
\hline 15 & & Neurotoxin II & P01427 & 6 & Naja oxiana \\
\hline 16 & & cobrotoxin b & CAA73829 & 3 & Naja atra \\
\hline 17 & & Cobrotoxin-b & P80958 & 4 & Naja atra \\
\hline 18 & & Alpha-cobratoxin & P01391 & 4 & Naja kaouthia \\
\hline 19 & & kappa-cobrotoxin & CAA76846 & 1 & Naja atra \\
\hline 20 & & Weak toxin 2 & Q8AY50 & 2 & Bungarus candidus \\
\hline 21 & & Weak neurotoxin 7 & P29181 & 7 & Naja naja \\
\hline 22 & & Weak neurotoxin 10 & Q802B2 & 1 & Naja sputatrix \\
\hline 23 & & Weak toxin CM-11 & P01401 & 4 & Naja haje haje \\
\hline 24 & & Weak toxin $\mathrm{S} 4 \mathrm{C} 11$ & P01400 & 5 & Naja melanoleuca \\
\hline 25 & & three-finger toxin precursor, partial & ADN67572 & 4 & Bungarus multicinctus \\
\hline 26 & & three-finger toxin precursor, partial & ADN67582 & 9 & Naja atra \\
\hline 27 & & three-finger toxin precursor, partial & ADN67583 & 1 & Naja atra \\
\hline 28 & & three-finger toxin precursor & ADN67579 & 1 & Naja atra \\
\hline 29 & & Muscarinic toxin-like protein 3 & P82464 & 3 & Naja kaouthia \\
\hline 30 & & Muscarinic toxin-like protein & Q9W727 & 4 & Bungarus multicinctus \\
\hline 31 & & Muscarinic toxin-like protein 2 & P82463 & 6 & Naja kaouthia \\
\hline 32 & & Muscarinic toxin-like protein 1 & P82462 & 2 & Naja kaouthia \\
\hline 33 & & Muscarinic toxin 38 & Q2VBN0 & 1 & Ophiophagus hannah \\
\hline 34 & & Alpha-elapitoxin-Nk2a & P01391 & 4 & Naja kaouthia \\
\hline 36 & & three finger toxin $V$ & ABX82866 & 1 & Walterinnesia aegyptia \\
\hline 37 & & Three finger toxin $\mathrm{W}-\mathrm{V}$ & C1IC49 & 3 & Walterinnesia aegyptia \\
\hline
\end{tabular}


Table 2. Cont.

\begin{tabular}{|c|c|c|c|c|c|}
\hline S. No & Protein Family & Protein & Accession Code & $\begin{array}{l}\text { Number of } \\
\text { Matched Peptides }\end{array}$ & $\begin{array}{l}\text { Homology with a Protein from } \\
\text { the Venom of Snake Species }\end{array}$ \\
\hline 38 & & Chain A, Putative Ancestral Mamba Toxin 1 & 5MG9_A & 1 & Dendroaspis angusticeps \\
\hline 39 & 3FTXs (cytotoxins) & cytotoxin 17 , partial & BAU24676 & 13 & Naja naja \\
\hline 40 & & Cytotoxin Vc-5 & Q9PS34 & 6 & Naja oxiana \\
\hline 41 & & Cytotoxin 3a & P86539 & 4 & Naja naja \\
\hline 42 & & Cytotoxin SP15c & P60308 & 13 & Naja atra \\
\hline 43 & & cardiotoxin $7 \mathrm{a}$ & AAB36929 & 2 & Naja atra \\
\hline 44 & & cardiotoxin 7a & Q91126 & 3 & Naja atra \\
\hline 46 & & Cytotoxin 8 & P86540 & 2 & Naja naja \\
\hline 47 & & Cytotoxin 1 & P01447 & 1 & Naja naja \\
\hline 48 & & Cytotoxin II & P01441 & 1 & Naja oxiana \\
\hline 49 & & Cytotoxin 5 & P25517 & 2 & Naja mossambica \\
\hline 50 & & Cardiotoxin-6 & Q98965 & 1 & Naja atra \\
\hline 51 & & Cytotoxin 10 & P86541 & 1 & Naja naja \\
\hline 52 & & Cytotoxin homolog 3 & P01473 & 1 & Naja melanoleuca \\
\hline 53 & & Cardiotoxin-like basic polypeptide ah & P0C547 & 2 & Naja atra \\
\hline 54 & & cardiotoxin $1 \mathrm{e}$ & AAA90960 & 4 & Naja atra \\
\hline 55 & Venom complement $C_{3}$-like & Venom factor & AAX86641 & 5 & Austrelaps superbus \\
\hline 56 & & Cobra venom factor & Q91132 & 31 & Naja kaouthia \\
\hline 57 & & Cobra venom factor gamma chain & Q91132 & 2 & Naja kaouthia \\
\hline 58 & & Cobra venom factor alpha chain & Q91132 & 2 & Naja kaouthia \\
\hline 59 & & cobra venom factor precursor & AAA68989 & 1 & Naja kaouthia \\
\hline 60 & & venom factor-like, partial & XP_025025833 & 2 & Python bivittatus \\
\hline 61 & & cobra venom factor 1 , partial & AX̄̄96620 & 13 & Ahaetulla prasina \\
\hline 62 & & cobra venom factor, partial & AXL95279 & 1 & Spilotes sulphureus \\
\hline 63 & & cobra venom factor, partial & AWX67646 & 1 & Boiga irregularis \\
\hline 64 & & Ophiophagus venom factor & $\mathrm{I} 2 \mathrm{C} 090$ & 3 & Ophiophagus hannah \\
\hline 66 & Venom Kunitz-type family & Kunitz-type serine protease inhibitor & P19859 & 1 & Naja naja \\
\hline 67 & & Kunitz-type serine protease inhibitor & P20229 & 6 & Naja naja \\
\hline 68 & & Kunitz-type serine protease inhibitor isoform 7 & ACY68703 & 1 & Parasuta nigriceps \\
\hline 69 & & Kunitz inhibitor b, partial & AAL30069 & 1 & Bungarus candidus \\
\hline 70 & & protease inhibitor & AFA90080 & 1 & Daboia siamensis \\
\hline 71 & & Venom basic protease inhibitor 2 & P00986 & 1 & Naja nivea \\
\hline 72 & & Kunitz-type protease inhibitor, partial & AWX67660 & 1 & Boiga irregularis \\
\hline 73 & & papilin-like, partial & XP_025032351 & 1 & Python bivittatus \\
\hline 74 & & Kunitz inhibitor I & ABX82867 & 1 & Walterinnesia aegyptia \\
\hline
\end{tabular}


Table 2. Cont.

\begin{tabular}{|c|c|c|c|c|c|}
\hline S. No & Protein Family & Protein & Accession Code & $\begin{array}{l}\text { Number of } \\
\text { Matched Peptides }\end{array}$ & $\begin{array}{l}\text { Homology with a Protein from } \\
\text { the Venom of Snake Species }\end{array}$ \\
\hline 75 & natriuretic peptide family & Natriuretic peptide Na-NP & D9IX97 & 2 & Naja atra \\
\hline 76 & & natriuretic peptide & ADK12001 & 1 & Naja atra \\
\hline 77 & & natriuretic peptide & ADK12001 & 1 & Naja atra \\
\hline 78 & cystatin & Cystatin & E3P6P4 & 4 & Naja kaouthia \\
\hline 79 & NGF-beta family & Venom nerve growth factor 2 & Q5YF89 & 2 & Naja sputatrix \\
\hline 80 & & Venom nerve growth factor 3 & Q3HXY1 & 7 & Pseudechis australis \\
\hline 81 & & nerve growth factor, partial & AAR24530 & 1 & Bitis gabonica \\
\hline 82 & & nerve growth factor & BAN82142 & 4 & Ovophis okinavensis \\
\hline 83 & & nerve growth factor beta chain precursor & A59218 & 1 & Naja kaouthia \\
\hline 84 & Ohanin/vespryn family. & Ohanin & P83234 & 4 & Ophiophagus hannah \\
\hline 85 & & Thaicobrin & P82885 & 2 & Naja kaouthia \\
\hline 86 & & Venom PRY-SPRY domain-containing protein, partial & AHZ08803 & 4 & Micropechis ikaheca \\
\hline 87 & & Vespryn & AEJ32004 & 1 & Crotalus adamanteus \\
\hline 88 & Insulin family & Insulin-like growth factor-binding protein 3, partial & XP_025032248 & 1 & Python bivittatus \\
\hline 89 & & Insulin enhancer protein ISL-1, partial & ETË72105 & 1 & Ophiophagus hannah \\
\hline 90 & Snake venom VEGF subfamily & $\begin{array}{l}\text { Snake venom vascular endothelial growth factor } \\
\text { toxin barietin }\end{array}$ & C0K3N1 & 1 & Bitis arietans \\
\hline 91 & CRISP & Cysteine-rich venom protein 25 & P84806 & 6 & Naja haje haje \\
\hline 92 & & cysteine-rich seceretory protein Ts-CRPM & ACE73574 & 2 & Trimeresurus stejnegeri \\
\hline 93 & & Cysteine-rich venom protein mossambin & P0DL16 & 2 & Naja mossambica \\
\hline 94 & & Cysteine-rich venom protein natrin-1 & Q7T1K6 & 16 & Naja atra \\
\hline 95 & & Cysteine-rich venom protein ophanin & Q7ZT98 & 3 & Ophiophagus hannah \\
\hline 96 & & cysteine-rich venom protein, partial & BAP39957 & 1 & Protobothrops flavoviridis \\
\hline 97 & & Cysteine-rich venom protein natrin-2 & Q7ZZN8 & 3 & Naja atra \\
\hline 98 & & Cysteine-rich seceretory protein Ts-CRPM & N-ACE73574 & 1 & Trimeresurus stejnegeri \\
\hline 99 & & Cysteine-rich venom protein $25-\mathrm{A}$ & P84807 & 1 & Naja haje haje \\
\hline 100 & & Helicopsin & P0DJG8 & 2 & Helicops angulatus \\
\hline 101 & & Cysteine-rich venom protein bucarin & P81993 & 1 & Bungarus candidus \\
\hline 102 & & Cysteine-rich venom protein latisemin & Q8JI38 & 1 & Laticauda semifasciata \\
\hline 103 & & Cysteine-rich venom protein ophanin & AAO62996 & 1 & Ophiophagus hannah \\
\hline 104 & & cysteine-rich secretory protein 4 , partial & AXL96584 & 2 & Borikenophis portoricensis \\
\hline 105 & & Cysteine-rich venom protein kaouthin-1 & P84805 & 1 & Naja kaouthia \\
\hline 106 & & Cysteine-rich venom protein annuliferin-b & P0DL15 & 1 & Naja annulifera \\
\hline 107 & & Cysteine-rich venom protein & AAP20603 & 2 & Naja atra \\
\hline 108 & & Cysteine-rich secretory protein & AJB84505 & 1 & Philodryas chamissonis \\
\hline 109 & & Opharin precursor & AAP81292 & 1 & Ophiophagus hannah \\
\hline 110 & & Cysteine rich secretory protein 2, partial & AXL96629 & 4 & Ahaetulla prasina \\
\hline
\end{tabular}


Table 2. Cont.

\begin{tabular}{|c|c|c|c|c|c|}
\hline S. No & Protein Family & Protein & Accession Code & $\begin{array}{l}\text { Number of } \\
\text { Matched Peptides }\end{array}$ & $\begin{array}{l}\text { Homology with a Protein from } \\
\text { the Venom of Snake Species }\end{array}$ \\
\hline 111 & Cathelicidin family & Cathelicidin-related protein precursor & ACF21000 & 1 & Naja atra \\
\hline 112 & \multirow[t]{2}{*}{ TGF-beta family } & Transforming growth factor beta-3, partial & ETE71774 & 1 & Ophiophagus hannah \\
\hline 113 & & Glial cell line-derived neurotrophic factor, partial & ETE67324 & 1 & Ophiophagus hannah \\
\hline 114 & \multirow[t]{20}{*}{ Phospholipase A2 } & Acidic phospholipase A2 3 & P60045 & 4 & Naja sagittifera \\
\hline 115 & & $85 \mathrm{kDa}$ calcium-independent phospholipase $\mathrm{A} 2$, partial & ETE71158 & 2 & Ophiophagus hannah \\
\hline 116 & & Acidic phospholipase A2 1 & P00596 & 4 & Naja kaouthia \\
\hline 117 & & Acidic phospholipase A2 1 & Q9W7J4 & 6 & Pseudonaja textilis \\
\hline 118 & & Basic phospholipase A2 T1-2 A chain & P84472 & 2 & Bungarus candidus \\
\hline 119 & & Acidic phospholipase A2 C & Q92086 & 5 & Naja sputatrix \\
\hline 120 & & Acidic phospholipase A2 1 & P00598 & 3 & Naja naja \\
\hline 121 & & Acidic phospholipase A2 2 & P60044 & 1 & Naja sagittifera \\
\hline 122 & & Acidic phospholipase A2 1 & P00596 & 4 & Naja kaouthia \\
\hline 123 & & Phospholipase A2 & BAA36403 & 1 & Naja kaouthia \\
\hline 124 & & Acidic phospholipase $\mathrm{A} 2$ beta-bungarotoxin $\mathrm{A} 4$ chain & P17934 & 2 & Bungarus multicinctus \\
\hline 125 & & Phospholipase A2-III & ABD24038 & 1 & Daboia russelii russelii \\
\hline 126 & & Basic phospholipase A2 homolog 1 & P10117 & 1 & Laticauda colubrina \\
\hline 127 & & Phospholipase A2 & AAL55555 & 1 & Hydrophis hardwickii \\
\hline 128 & & Phospholipase A2 & P15445 (2WQ5) & 1 & Naja naja \\
\hline 129 & & Phospholipase A2 3 & P21792 & 3 & Micrurus nigrocinctus \\
\hline 130 & & Phospholipase A2I precursor & BAC77655 & 1 & Bungarus flaviceps \\
\hline 131 & & Phospholipase a2 & CAA45372 & 1 & Naja naja \\
\hline 132 & & Phospholipase A2 & AAA66029 & 1 & Naja naja \\
\hline 133 & & Phosphatidylcholine 2-acylhydrolase T1-2 A & P84472 & 2 & Bungarus candidus \\
\hline 134 & Phospholipase B-like family & Phospholipase B-like 1, partial & ETE59578 & 1 & Ophiophagus hannah \\
\hline 135 & \multirow[t]{3}{*}{ CNF-like-inhibitor family } & \multirow{3}{*}{$\begin{array}{l}\text { Phospholipase A2 inhibitor subunit gamma A } \\
\text { Phospholipase A2 inhibitor beta subunit } \\
\text { isoform OMI-2B } \\
\text { Phospholipase A2 inhibitor } 31 \mathrm{kDa} \text { subunit }\end{array}$} & Q9PWI4 & 1 & Elaphe quadrivirgata \\
\hline 136 & & & AAF21049 & 1 & Oxyuranus microlepidotus \\
\hline 137 & & & Q7LZI1 & 1 & Naja kaouthia \\
\hline
\end{tabular}


Table 2. Cont.

\begin{tabular}{|c|c|c|c|c|c|}
\hline S. No & Protein Family & Protein & Accession Code & $\begin{array}{l}\text { Number of } \\
\text { Matched Peptides }\end{array}$ & $\begin{array}{l}\text { Homology with a Protein from } \\
\text { the Venom of Snake Species }\end{array}$ \\
\hline 138 & \multirow[t]{16}{*}{ SVMP (PIII) } & Acutolysin e precursor & AAD27891 & 1 & Deinagkistrodon acutus \\
\hline 139 & & Snake venom metalloproteinase & D5LMJ3 & 12 & Naja atra \\
\hline 140 & & Snake venom metalloproteinase & D3TTC1 & 20 & Naja atra \\
\hline 141 & & Snake venom metalloproteinase & D3TTC2 & 8 & Naja atra \\
\hline 142 & & $\begin{array}{l}\text { Snake venom metalloproteinase-disintegrin- } \\
\text { like mocarhagin }\end{array}$ & Q10749 & 7 & Naja mossambica \\
\hline 143 & & Snake venom metalloproteinase & Q9PVK7 & 5 & Naja kaouthia \\
\hline 144 & & Snake venom metalloproteinase & A8QL49 & 2 & Bungarus multicinctus \\
\hline 145 & & Snake venom metalloproteinase & P82942 & 8 & Naja kaouthia \\
\hline 146 & & Snake venom metalloprotease(ADAM) & ACS74986 & 1 & Philodryas olfersii \\
\hline 147 & & Snake venom metalloproteinase 27 , partial & AXL96577 & 1 & Borikenophis portoricensis \\
\hline 148 & & $\begin{array}{l}\text { Disintegrin and metalloproteinase domain-containing } \\
\text { protein } 21 \text {, partial }\end{array}$ & ETE71596 & 2 & Ophiophagus hannah \\
\hline 149 & & Microlepidotease-1 & ABQ01137 & 1 & Oxyuranus microlepidotus \\
\hline 150 & & Metalloproteinase atrase B, partial & ADD14036 & 1 & Naja atra \\
\hline 151 & & Metalloproteinase 7, partial & AXL96626 & 1 & Ahaetulla prasina \\
\hline 152 & & Snake venom metalloproteinase & P0DM46 & 1 & Micrurus corallinus \\
\hline 153 & & K-like metalloprotease precursor, partial & ACN50005 & 1 & Naja atra \\
\hline 154 & $\begin{array}{l}\text { Snake venom serine proteinase } \\
\text { (peptidase S1 family) }\end{array}$ & Tissue-type plasminogen activator, partial & ETE66683 & 3 & Ophiophagus hannah \\
\hline 155 & & Tissue-type plasminogen activator-like, partial & XP_025033187 & 3 & Python bivittatus \\
\hline 156 & & Complement factor B precursor & AAR21601 & 1 & Naja kaouthia \\
\hline 157 & & Thrombin-like enzyme TLP & P86545 & 2 & Naja naja \\
\hline 158 & & Serine endopeptidase & AUS82567 & 1 & Crotalus tigris \\
\hline 159 & & Snake venom serine protease NaSP & A8QL53 & 1 & Naja atra \\
\hline 160 & & Snake venom serine protease catroxase-1 & Q8QHK3 & 1 & Crotalus atrox \\
\hline 161 & & Anionic trypsin-1-like & XP_007434941 & 1 & Python bivittatus \\
\hline 162 & & Coagulation factor $\mathrm{X}$ isoform 1 , partial & ETE73401 & 1 & Ophiophagus hannah \\
\hline 163 & & Serine endopeptidase & AUS82552 & 1 & Crotalus scutulatus \\
\hline 164 & 5 -nucleotidase family & 5-nucleotidase & BAP39972 & 5 & Protobothrops flavoviridis \\
\hline 165 & & Venom 5'-nucleotidase & A0A2I4HXH5 & 3 & Naja atra \\
\hline 166 & & 5'-nucleotidase, partial & ETE67245 & 1 & Ophiophagus hannah \\
\hline 167 & & Snake venom $5^{\prime}$-nucleotidase & B6EWW8 & 1 & Gloydius brevicaudus \\
\hline
\end{tabular}


Table 2. Cont.

\begin{tabular}{|c|c|c|c|c|c|}
\hline S. No & Protein Family & Protein & Accession Code & $\begin{array}{l}\text { Number of } \\
\text { Matched Peptides }\end{array}$ & $\begin{array}{l}\text { Homology with a Protein from } \\
\text { the Venom of Snake Species }\end{array}$ \\
\hline 168 & \multirow[t]{2}{*}{ Aminopeptidase } & Aminopeptidase $\mathrm{N}$, partial & ETE61021 & 1 & Ophiophagus hannah \\
\hline 169 & & Aminopeptidase $\mathrm{N}$ & BAG82599 & 6 & Gloydius brevicaudus \\
\hline 170 & Type-B carboxylesterase/lipase & $\mathrm{N}$-acetylcholinesterase & AAC59905 & 1 & Bungarus fasciatus \\
\hline 171 & \multirow[t]{4}{*}{ Phosphodiesterase } & Snake venom Phosphodiesterase & A0A2D0TC04 & 3 & Naja atra \\
\hline 172 & & Phosphodiesterase & АHJ80885 & 1 & Macrovipera lebetina \\
\hline 173 & & Phosphodiesterase, partial & AXL96599 & 2 & Borikenophis portoricensis \\
\hline 174 & & Phosphodiesterase & BAN89425 & 2 & Ovophis okinavensis \\
\hline 175 & \multirow[t]{11}{*}{ Flavin monoamine oxidase family } & L-amino acid oxidase, partial & AAZ08620 & 1 & Daboia siamensis \\
\hline 176 & & L-amino acid oxidase, partial & AVX27607 & 4 & Naja atra \\
\hline 177 & & L-amino-acid oxidase & Q4JHE1 & 5 & Pseudechis australis \\
\hline 178 & & L-amino-acid oxidase & P0C2D5 & 1 & Protobothrops flavoviridis \\
\hline 179 & & L-amino-acid oxidase & A8QL51 & 1 & Bungarus multicinctus \\
\hline 180 & & L-amino-acid oxidase & Q4JHE3 & 3 & Oxyuranus scutellatus scutellatus \\
\hline 181 & & L-amino acid oxidase, partial & AVX27607 & 4 & Naja atra \\
\hline 182 & & L-amino-acid oxidase & A8QL58 & 6 & Naja atra \\
\hline 183 & & L-amino-acid oxidase & Q4JHE3 & 3 & Oxyuranus scutellatus scutellatus \\
\hline 184 & & L-amino acid oxidase precursor & AAY89682 & 2 & Pseudechis australis \\
\hline 185 & & L-amino-acid oxidase & CAQ72894 & 1 & Echis ocellatus \\
\hline 186 & \multirow[t]{2}{*}{ True venom lectin family } & C-type lectin galactose-binding isoform & D2YVK1 & 2 & Hoplocephalus stephensii \\
\hline 187 & & BJcuL precursor & AAQ92957 & 1 & Bothrops jararacussu \\
\hline 188 & \multirow[t]{2}{*}{ Ankyrin SOCS box (ASB) family } & Ankyrin repeat and SOCS box protein 7, partial & ETE63895 & 1 & Ophiophagus hannah \\
\hline 189 & & Ankyrin repeat domain-containing protein 50 , partial & ETE61041 & 1 & Ophiophagus hannah \\
\hline 190 & Transferrin & Transferrin & CAK18221 & 2 & Natrix natrix \\
\hline 191 & \multirow[t]{3}{*}{ Cobra serum albumin } & Cobra serum albumin & S59517 & 1 & Naja kaouthia \\
\hline 192 & & Serum albumin precursor & S59517 & 3 & Naja naja \\
\hline 193 & & Cobra serum albumin & CAA55333 & 3 & Naja naja \\
\hline 194 & $\begin{array}{l}\text { Serum } \\
\text { albumin/Alpha-fetoprotein/Afamin }\end{array}$ & Alpha-fetoprotein, partial & ETE59846 & 3 & Ophiophagus hannah \\
\hline 195 & \multirow{3}{*}{$\begin{array}{l}\text { Leucine repeat } \\
\text { Small leucine-rich proteoglycan } \\
\text { (SLRP) family }\end{array}$} & Leucine-rich repeat neuronal protein 4 & XP_007424790 & 1 & Python bivittatus \\
\hline 196 & & Decorin, partial & ETE60606 & 1 & Ophiophagus hannah \\
\hline 197 & & $\begin{array}{l}\text { Leucine-rich repeat and WD repeat- } \\
\text { containing protein, partial }\end{array}$ & ETE61323 & 1 & Ophiophagus hannah \\
\hline
\end{tabular}


Table 2. Cont

\begin{tabular}{|c|c|c|c|c|c|}
\hline S. No & Protein Family & Protein & Accession Code & $\begin{array}{l}\text { Number of } \\
\text { Matched Peptides }\end{array}$ & $\begin{array}{l}\text { Homology with a Protein from } \\
\text { the Venom of Snake Species }\end{array}$ \\
\hline 198 & \multirow[t]{2}{*}{ XPG/RAD2 endonuclease family } & Endonuclease domain-containing 1 protein, partial & ETE59939 & 2 & Ophiophagus hannah \\
\hline 199 & & Deoxyribonuclease-2-alpha, partial & ETE73206 & 1 & Ophiophagus hannah \\
\hline 200 & NHS Family & NHS-like protein 1, partial & ETE71282 & 1 & Ophiophagus hannah \\
\hline 201 & \multirow{6}{*}{ G-protein coupled receptor } & G-protein coupled receptor 161 & XP_007428215 & 1 & Python bivittatus \\
\hline 202 & & Putative G-protein coupled receptor & ETE61591 & 2 & Ophiophagus hannah \\
\hline 203 & & Melanocyte-stimulating hormone receptor, partial & ETE69163 & 1 & Ophiophagus hannah \\
\hline 204 & & Latrophilin-2, partial & ETE73569 & 1 & Ophiophagus hannah \\
\hline 205 & & $\begin{array}{l}\text { Cadherin EGF LAG seven-pass G-type } \\
\text { receptor 2, partial }\end{array}$ & ETE72621 & 1 & Ophiophagus hannah \\
\hline 206 & & Putative G-protein coupled receptor, partial & ETE70400 & 1 & Ophiophagus hannah \\
\hline 207 & \multirow{6}{*}{ Zinc finger protein } & Thioredoxin domain-containing protein 11 , partial & ETE72118 & 1 & Ophiophagus hannah \\
\hline 208 & & Zinc finger protein 91-like isoform X2 & XP_007443313 & 1 & Python bivittatus \\
\hline 209 & & Zinc finger protein 687 isoform $\mathrm{X} 1$ & XP_025027118 & 1 & Python bivittatus \\
\hline 210 & & Zinc finger FYVE domain-containing protein 16 , partial & ETÉ66135 & 1 & Ophiophagus hannah \\
\hline 211 & & $\begin{array}{l}\text { Zinc finger and BTB domain-containing } \\
\text { protein 14, partial }\end{array}$ & XP_026555390 & 1 & Pseudonaja textilis \\
\hline 212 & & Zinc finger protein 609 isoform $\mathrm{X} 1$ & XP_007426825 & 1 & Python bivittatus \\
\hline 213 & \multirow[t]{5}{*}{ Ras-like protein } & Ras GTPase-activating protein 3, partial & ETE71570 & 1 & Ophiophagus hannah \\
\hline 214 & & Rac GTPase-activating protein 1 , partial & ETE61861 & 1 & Ophiophagus hannah \\
\hline 215 & & Ras-related protein Rap-2a, partial & ETE66602 & 1 & Ophiophagus hannah \\
\hline 216 & & RalA-binding protein 1 , partial & ETE67818 & 1 & Ophiophagus hannah \\
\hline 217 & & Guanylate-binding protein 1-like & XP_007444632 & 1 & Python bivittatus \\
\hline 218 & Glutathione peroxidase family & Glutathione peroxidase 3, partial & ETE68810 & 9 & Ophiophagus hannah \\
\hline 219 & \multirow[t]{6}{*}{ Protein family not assigned } & Octapeptide-repeat protein $\mathrm{T} 2$, partial & ETE65834 & 1 & Ophiophagus hannah \\
\hline 220 & & Atrial natriuretic peptide receptor 2 , partial & ETE58463 & 1 & Ophiophagus hannah \\
\hline 221 & & Octapeptide-repeat protein $\mathrm{T} 2$, partial & ETE61441 & 1 & Ophiophagus hannah \\
\hline 222 & & GAS2-like protein 2, partial & ETE67730 & 1 & Ophiophagus hannah \\
\hline 223 & & Exocyst complex component 3, partial & ETE60130 & 1 & Ophiophagus hannah \\
\hline 224 & & Vacuolar protein sorting-associated protein 54 & ETE70627 & 1 & Ophiophagus hannah \\
\hline
\end{tabular}


Table 2. Cont.

\begin{tabular}{|c|c|c|c|c|c|}
\hline S. No & Protein Family & Protein & Accession Code & $\begin{array}{l}\text { Number of } \\
\text { Matched Peptides }\end{array}$ & $\begin{array}{l}\text { Homology with a Protein from } \\
\text { the Venom of Snake Species }\end{array}$ \\
\hline 225 & & Cohesin subunit SA-2, partial & ETE63002 & & Ophiophagus hannah \\
\hline 226 & & Zona pellucida sperm-binding protein 3 receptor, partial & ETE59512 & 1 & Ophiophagus hannah \\
\hline 227 & & Ubiquitin carboxyl-terminal hydrolase 32 , partial & ETE63263 & 1 & Ophiophagus hannah \\
\hline 228 & & Putative E3 ubiquitin-protein ligase UBR7 & ETE67503 & 1 & Ophiophagus hannah \\
\hline 229 & & Mdm2-binding protein, partial & ETE64533 & 1 & Ophiophagus hannah \\
\hline 230 & & E3 ubiquitin-protein ligase TTC3, partial & ETE73451 & 1 & Ophiophagus hannah \\
\hline 231 & & Protocadherin-23 & XP_007425673 & 1 & Python bivittatus \\
\hline 232 & & Nucleolar complex protein 4-like protein, partial & ETE59886 & 1 & Ophiophagus hannah \\
\hline 233 & & $\begin{array}{l}\text { Low molecular weight phosphotyrosine protein } \\
\text { phosphatase, partial }\end{array}$ & ETE66708 & 1 & Ophiophagus hannah \\
\hline 234 & & $\begin{array}{l}\text { Major histocompatibility complex class } \\
\text { I-related protein, partial }\end{array}$ & ETE56816 & 1 & Ophiophagus hannah \\
\hline 235 & & Beta-2-microglobulin, partial & ETE58426 & 1 & Ophiophagus hannah \\
\hline 236 & & GRAM domain-containing protein $1 \mathrm{~B}$, partial & ETE59875 & 1 & Ophiophagus hannah \\
\hline 237 & & $\begin{array}{l}\text { von Willebrand factor A domain-containing } \\
\text { protein } 3 \mathrm{~B} \text {, partial }\end{array}$ & ETE71898 & 1 & Ophiophagus hannah \\
\hline 238 & & Homeobox protein PKNOX1, partial & XP_007435014 & 1 & Python bivittatus \\
\hline 239 & & Homeobox protein prophet of Pit-1, partial & ETE69018 & 1 & Ophiophagus hannah \\
\hline 240 & & Homeobox protein cut-like 2, partial & ETE71612 & 1 & \\
\hline 241 & & Inosine-uridine preferring nucleoside hydrolase, partial & ETE68936 & 1 & Ophiophagus hannah \\
\hline 242 & & Signal recognition particle receptor subunit beta & ETE61181 & 1 & Ophiophagus hannah \\
\hline 243 & & Sodium channel protein type 1 subunit alpha & XP_025024892 & 1 & Python bivittatus \\
\hline 244 & & Small serum protein-4 & BAJ14709 & 1 & Gloydius blomhoffii blomhoffii \\
\hline 245 & & Clathrin heavy chain 1 , partial & ETE68739 & 1 & Ophiophagus hannah \\
\hline 246 & & Neutral amino acid transporter A, partial & ETE71889 & 1 & Ophiophagus hannah \\
\hline 247 & & Bystin & ETE67512 & 1 & Ophiophagus hannah \\
\hline 248 & & Peroxisome biogenesis factor 1 -like isoform $\mathrm{X} 1$ & XP_025032182 & 1 & Python bivittatus \\
\hline 249 & & Dapper-like 1, partial & ETE59781 & 1 & Ophiophagus hannah \\
\hline 250 & & Protein patched-like 2, partial & ETE72035 & 1 & Ophiophagus hannah \\
\hline 251 & & Keratin, type II cytoskeletal 1, partial & ETE67131 & 1 & Ophiophagus hannah \\
\hline 252 & & Keratin, type II cytoskeletal 6A-like & XP_007441333 & 1 & Python bivittatus \\
\hline 253 & & Cytosolic carboxypeptidase 2, partial & ETË72716 & 1 & Ophiophagus hannah \\
\hline
\end{tabular}


Table 2. Cont.

\begin{tabular}{|c|c|c|c|c|c|}
\hline S. No & Protein Family & Protein & Accession Code & $\begin{array}{l}\text { Number of } \\
\text { Matched Peptides }\end{array}$ & $\begin{array}{l}\text { Homology with a Protein from } \\
\text { the Venom of Snake Species }\end{array}$ \\
\hline 254 & & NADH dehydrogenase subunit 4 & YP_003540795 & 1 & Hypsiglena ochrorhyncha klauberi \\
\hline 255 & & Olfactory receptor 2D2-like & XP_007442854 & 1 & Python bivittatus \\
\hline 256 & & Histone-lysine N-methyltransferase SETD1B, partial & ETE63606 & 1 & Ophiophagus hannah \\
\hline 257 & & Helicase SRCAP, partial & ETE66458 & 1 & Ophiophagus hannah \\
\hline 258 & & Tyrosine-protein phosphatase non-receptor type 11-like & XP_015743235 & 1 & Python bivittatus \\
\hline 259 & & Glycerol-3-phosphate acyltransferase 4 & ETE64295 & 1 & Ophiophagus hannah \\
\hline 260 & & NEDD4-binding protein 1 , partial & ETE71789 & 1 & Ophiophagus hannah \\
\hline 261 & & Nuclear pore complex protein, partial & ETE72717 & 1 & Ophiophagus hannah \\
\hline 262 & & G1/S-specific cyclin-E1, partial & ETE69419 & 1 & Ophiophagus hannah \\
\hline 263 & & Copine-3 & ETE62235 & 1 & Ophiophagus hannah \\
\hline 264 & & Disks large-like 1, partial & ETE60775 & 1 & Ophiophagus hannah \\
\hline 265 & & Tumor necrosis factor receptor superfamily member $11 \mathrm{~B}$ & ETE67452 & 1 & Ophiophagus hannah \\
\hline 266 & & Extracellular matrix protein 1 , partial & ETE63009 & 3 & Ophiophagus hannah \\
\hline 267 & & Protein PRRC2C isoform X7 & XP_025025988 & 1 & Python bivittatus \\
\hline 268 & & Protein dispatched-like 2, partial & ETE65280 & 1 & Ophiophagus hannah \\
\hline 269 & & Cytoplasmic FMR1-interacting protein 1 & ETE70074 & 1 & Ophiophagus hannah \\
\hline 270 & & Sushi domain-containing protein 2 isoform $\mathrm{X} 1$ & XP_007439094 & 1 & Python bivittatus \\
\hline 271 & & POU domain, class 2, transcription factor 1, partial & ETE68887 & 1 & Ophiophagus hannah \\
\hline 272 & & Vomeronasal type-2 receptor 26 -like & XP_015746172 & 1 & Python bivittatus \\
\hline 273 & & snRNA-activating protein complex subunit 4 , partial & ETE66257 & 1 & Ophiophagus hannah \\
\hline 274 & & $\begin{array}{l}\text { Small subunit processome component } 20 \text {-like protein, } \\
\text { partia }\end{array}$ & ETE62675 & 1 & Ophiophagus hannah \\
\hline 275 & & Retrotransposon-derived protein PEG10, partial & ETE60414 & 1 & Ophiophagus hannah \\
\hline 276 & & Heterogeneous nuclear ribonucleoprotein $\mathrm{R}$ & ETE70095 & 1 & Ophiophagus hannah \\
\hline 277 & & Sacsin, partial & ETE73074 & 1 & Ophiophagus hannah \\
\hline 278 & & Trafficking protein particle complex subunit 3 & XP_007439119 & 1 & Python bivittatus \\
\hline 279 & & Putative protein C4orf34 & ETE61848 & 1 & Ophiophagus hannah \\
\hline 280 & & Sulfate transporter, partial & ETE72250 & 1 & Ophiophagus hannah \\
\hline 281 & & $\begin{array}{l}\text { Solute carrier family } 2 \text {, facilitated glucose transporter } \\
\text { member } 11 \text {, partial }\end{array}$ & ETE65979 & 1 & Ophiophagus hannah \\
\hline 282 & & Solute carrier family 25 member 47 , partial & ETE64737 & 1 & Ophiophagus hannah \\
\hline 283 & & Citrate synthase, mitochondrial & ETE71902 & 1 & Ophiophagus hannah \\
\hline
\end{tabular}


Table 2. Cont

\begin{tabular}{|c|c|c|c|c|c|}
\hline S. No & Protein Family & Protein & Accession Code & $\begin{array}{l}\text { Number of } \\
\text { Matched Peptides }\end{array}$ & $\begin{array}{l}\text { Homology with a Protein from } \\
\text { the Venom of Snake Species }\end{array}$ \\
\hline 284 & & Separin, partial & ETE71706 & 1 & Ophiophagus hannah \\
\hline 285 & & 5,6-dihydroxyindole-2-carboxylic acid oxidase, partial & ETE63759 & 1 & Ophiophagus hannah \\
\hline 286 & & Protocadherin-15, partial & ETE73122 & 1 & Ophiophagus hannah \\
\hline 287 & & $\begin{array}{l}\text { Tumor necrosis factor receptor superfamily member 11B } \\
\text { isoform X2 }\end{array}$ & XP_025019261 & 1 & Python bivittatus \\
\hline 288 & & $\begin{array}{l}\text { Microtubule-actin cross-linking factor } 1 \text {, isoforms } \\
1 / 2 / 3 / 5 \text {, partial }\end{array}$ & ETE72267 & 1 & Ophiophagus hannah \\
\hline 289 & & Ubiquitin carboxyl-terminal hydrolase CYLD & XP_015680147 & 1 & Protobothrops mucrosquamatus \\
\hline 290 & & Peroxidasin, partial & ETE57820 & 1 & Ophiophagus hannah \\
\hline 291 & & Serine palmitoyltransferase small subunit B & XP_025028624 & 1 & Python bivittatus \\
\hline 292 & & C-terminal-binding protein 1 , partial & ETE64323 & 1 & Ophiophagus hannah \\
\hline 293 & & StAR-related lipid transfer protein 13 & ETE69978 & 1 & Ophiophagus hannah \\
\hline 294 & & Ty3b-i, partial & ETE59080 & 1 & Ophiophagus hannah \\
\hline 295 & & E3 ubiquitin-protein ligase RNF19B, partial & ETE68153 & 1 & Ophiophagus hannah \\
\hline 296 & & PDZ domain-containing protein 6, partial & ETE69093 & 1 & Ophiophagus hannah \\
\hline 297 & & Nebulin, partial & ETE70906 & 2 & Ophiophagus hannah \\
\hline 298 & & Myoferlin, partial & ETE66870 & 1 & Ophiophagus hannah \\
\hline 299 & & Protein mago nashi-like 2 & ETE70612 & 1 & Ophiophagus hannah \\
\hline 300 & & $\mathrm{H}(+) / \mathrm{Cl}(-)$ exchange transporter 7 , partial & ETE72134 & 1 & Ophiophagus hannah \\
\hline 301 & & Membrane cofactor protein-like & XP_025021316 & 2 & Python bivittatus \\
\hline 302 & & Holliday junction recognition protein isoform $\mathrm{X} 1$ & XP_025025001 & 1 & Python bivittatus \\
\hline 303 & & Adenylate cyclase type 2 , partial & ETE62750 & 1 & Ophiophagus hannah \\
\hline 304 & & Transmembrane protein, partial & ETE59610 & 1 & Ophiophagus hannah \\
\hline 305 & & Transmembrane protein, partial & ETE58244 & 1 & Ophiophagus hannah \\
\hline 306 & & Type I inositol 3,4-bisphosphate 4-phosphatase & XP_015686159 & 1 & Protobothrops mucrosquamatus \\
\hline 307 & & $\begin{array}{l}\text { Complement decay-accelerating factor transmembrane } \\
\text { isoform, partial }\end{array}$ & ETE63384 & 8 & Ophiophagus hannah \\
\hline 308 & & $\begin{array}{l}\text { NACHT, LRR and PYD domains-containing protein } \\
\text { 6(Belongs to NLRP family) }\end{array}$ & XP_015679160 & 1 & Protobothrops mucrosquamatus \\
\hline 309 & & Ubiquitin carboxyl-terminal hydrolase 24 & ETE67725 & 1 & Ophiophagus hannah \\
\hline 310 & & Epiplakin, partial & ETE58258 & 1 & Ophiophagus hannah \\
\hline 311 & & $5^{\prime}$ nucleotidase, partial & AXL95273 & 1 & Spilotes sulphureus \\
\hline 312 & & GTP-binding protein 2, partial & ETE70473 & 1 & Ophiophagus hannah \\
\hline 313 & & Transmembrane protein 41A & XP_007420693 & 1 & Python bivittatus \\
\hline 314 & & Serine/threonine-protein kinase $\mathrm{TAO} 2$, partial & ETË67077 & 1 & Ophiophagus hannah \\
\hline
\end{tabular}


Table 2. Cont.

\begin{tabular}{|c|c|c|c|c|c|}
\hline S. No & Protein Family & Protein & Accession Code & $\begin{array}{l}\text { Number of } \\
\text { Matched Peptides }\end{array}$ & $\begin{array}{l}\text { Homology with a Protein from } \\
\text { the Venom of Snake Species }\end{array}$ \\
\hline 315 & & Serine/threonine-protein kinase WNK1, partial & ETE61641 & 1 & Ophiophagus hannah \\
\hline 316 & & cilia- and flagella-associated protein 57 -like, partial & XP_007436852 & 1 & Python bivittatus \\
\hline 317 & & Lymphocyte antigen 6 complex locus protein G6d & ETË61452 & 1 & Ophiophagus hannah \\
\hline 318 & & Histamine H3 receptor, partial & ETE72972 & 1 & Ophiophagus hannah \\
\hline 319 & & $\begin{array}{l}\text { Glycerol-3-phosphate acyltransferase 1, } \\
\text { mitochondrial, partial }\end{array}$ & ETE59719 & 1 & Ophiophagus hannah \\
\hline 320 & & $\begin{array}{l}\text { Cleft lip and palate transmembrane protein 1-like } \\
\text { protein, partial }\end{array}$ & ETE61569 & 1 & Ophiophagus hannah \\
\hline 321 & & Complement factor B precursor & AAR21601 & 1 & Naja kaouthia \\
\hline 322 & & Selenocysteine lyase & XP_015669194 & 1 & Protobothrops mucrosquamatus \\
\hline 323 & & Serine/threonine-protein kinase Nek1, partial & ETE68306 & 1 & Ophiophagus hannah \\
\hline 324 & & Collagen alpha-1(IV) chain, partial & ETE60834 & 1 & Ophiophagus hannah \\
\hline 325 & & DmX-like protein 2, partial & ETE63888 & 1 & Ophiophagus hannah \\
\hline 326 & & Aldehyde dehydrogenase family 3 member B1, partial & ETE72723 & 1 & Ophiophagus hannah \\
\hline 327 & & Putative ATP-dependent RNA helicase DHX40, partial & ETE68740 & 1 & Ophiophagus hannah \\
\hline 328 & & Immunoglobulin Y2 heavy chain, partial & AFR33766 & 1 & Python bivittatus \\
\hline 329 & & Myomesin-1, partial & ETE65385 & 1 & Ophiophagus hannah \\
\hline 330 & & $\begin{array}{l}\text { Cyclic AMP-dependent transcription } \\
\text { factor ATF-1, partial }\end{array}$ & ETE65149 & 1 & Ophiophagus hannah \\
\hline 331 & & Toll-like receptor 4, partial & ETE72495 & 1 & Ophiophagus hannah \\
\hline 332 & & Serine palmitoyltransferase small subunit $B$ & XP_025028624 & 1 & Python bivittatus \\
\hline 333 & & $\begin{array}{l}\text { Histone-lysine N-methyltransferase, H3 lysine-79 } \\
\text { specific, partial }\end{array}$ & ETE65559 & 1 & Ophiophagus hannah \\
\hline 334 & & Creatine kinase B-type, partial & ETE69249 & 1 & Ophiophagus hannah \\
\hline 335 & & Fibroblast growth factor 3, partial & ETE69378 & 1 & Ophiophagus hannah \\
\hline 336 & & RB1-inducible coiled-coil protein 1 , partial & ETE67067 & 1 & Ophiophagus hannah \\
\hline 337 & & Phosphoinositide 3-kinase regulatory subunit 5, partial & ETE74144 & 1 & Ophiophagus hannah \\
\hline 338 & & $\begin{array}{l}\text { Cadherin EGF LAG seven-pass G-type } \\
\text { receptor 2, partial }\end{array}$ & ETE72621 & 1 & Ophiophagus hannah \\
\hline 339 & & Trafficking kinesin-binding protein 1 , partial & ETE68220 & 1 & Ophiophagus hannah \\
\hline 340 & & YTH domain family protein 2 & ETE65464 & 1 & Ophiophagus hannah \\
\hline 341 & & Vigilin, partial & ETE61946 & 1 & Ophiophagus hannah \\
\hline 342 & & $39 \mathrm{~S}$ ribosomal protein L44, mitochondrial, partial & ETE68399 & 1 & Ophiophagus hannah \\
\hline
\end{tabular}


Table 2. Cont.

\begin{tabular}{|c|c|c|c|c|c|}
\hline S. No & Protein Family & Protein & Accession Code & $\begin{array}{l}\text { Number of } \\
\text { Matched Peptides }\end{array}$ & $\begin{array}{l}\text { Homology with a Protein from } \\
\text { the Venom of Snake Species }\end{array}$ \\
\hline 343 & & Pseudouridine-5'-monophosphatase, partial & ETE71697 & 1 & Ophiophagus hannah \\
\hline 344 & & Kelch-like protein 13 , partial & ETE71947 & 1 & Ophiophagus hannah \\
\hline 345 & & Maleylacetoacetate isomerase & ETE68752 & 1 & Ophiophagus hannah \\
\hline 346 & & Neurexophilin-2, partial & ETE71784 & 1 & Ophiophagus hannah \\
\hline 347 & & Myocyte-specific enhancer factor $2 \mathrm{~A}$ isoform X1 & XP_007425135 & 1 & Python bivittatus \\
\hline 348 & & Membrane cofactor protein-like isoform X1 & XP_015743425 & 1 & Python bivittatus \\
\hline 349 & & Ninein-like protein, partial & ETE70166 & 1 & Ophiophagus hannah \\
\hline 350 & & Keratin, type I cytoskeletal 19, partial & ETE70217 & 1 & Ophiophagus hannah \\
\hline 351 & & Intraflagellar transport protein 88 -like protein & ETE73657 & 1 & Ophiophagus hannah \\
\hline 352 & & Complement receptor type 2 , partial & ETE63383 & 1 & Ophiophagus hannah \\
\hline 353 & & Complement decay-accelerating factor, partial & ETE59511 & 1 & Ophiophagus hannah \\
\hline 354 & & Keratin, type II cytoskeletal 5-like & XP_025030548 & 1 & Python bivittatus \\
\hline 355 & & 7-dehydrocholesterol reductase, partial & ETE67784 & 1 & Ophiophagus hannah \\
\hline 356 & & La-related protein $4 \mathrm{~B}$ & ETE62671 & 1 & Ophiophagus hannah \\
\hline 357 & & Intelectin-1a, partial & ETE57886 & 1 & Ophiophagus hannah \\
\hline 358 & & Cation-independent mannose-6-phosphate receptor & ETE64374 & 2 & Ophiophagus hannah \\
\hline 359 & & Cerebellin- 4 & ETE65277 & 1 & Ophiophagus hannah \\
\hline 360 & & $\begin{array}{l}\text { C3 and PZP-like alpha-2-macroglobulin } \\
\text { domain-containing protein } 8 \text {, partial }\end{array}$ & ASU45032 & 1 & Ophiophagus hannah \\
\hline 361 & & Neuronal PAS domain-containing protein 2, partial & ETE63668 & 1 & Ophiophagus hannah \\
\hline 362 & & Interferon-induced transmembrane protein 10 , partial & ETE66904 & 1 & Ophiophagus hannah \\
\hline 363 & & Myotubularin-related protein 11, partial & ETE72068 & 1 & Ophiophagus hannah \\
\hline 364 & & Tyrosyl-DNA phosphodiesterase 2 & XP_026525751 & 1 & Notechis scutatus \\
\hline 365 & & Phosphoinositide 3 -kinase regulatory subunit 5 , partial & ETE74144 & 1 & Ophiophagus hannah \\
\hline
\end{tabular}

The bold text indicates the proteins identified to have $\mathrm{N}$-terminal acetylation. 
Table 3. Summary of the venom proteome of N. oxiana.

\begin{tabular}{|c|c|c|c|c|c|}
\hline S. No. & Protein Family & Protein & Accession Code & $\begin{array}{l}\text { Number of } \\
\text { Matched Peptides }\end{array}$ & $\begin{array}{l}\text { Homology with Protein from the } \\
\text { Venom of Snake Species }\end{array}$ \\
\hline 1 & 3FTX (Neurotoxin & Neurotoxin homolog NL1 & Q9DEQ3 & 1 & Naja atra \\
\hline 2 & & Short neurotoxin SNTX-1 & A6MFK6 & 1 & Demansia vestigiata \\
\hline 3 & & Neurotoxin II & P01427 & 1 & Naja oxiana \\
\hline 4 & & Cobrotoxin-b & P80958 & 1 & Naja atra \\
\hline 5 & & Alpha-cobratoxin & P01391 & 3 & Naja kaouthia \\
\hline 6 & & Weak toxin 2 & Q8AY50 & 2 & Bungarus candidus \\
\hline 7 & & Weak neurotoxin 6 & $\mathrm{O} 42256$ & 1 & Naja sputatrix \\
\hline 8 & & Weak neurotoxin 7 & P29181 & 2 & Naja naja \\
\hline 9 & & Weak toxin $\mathrm{S} 4 \mathrm{C} 11$ & P01400 & 1 & Naja melanoleuca \\
\hline 10 & & Muscarinic toxin-like protein 3 & P82464 & 4 & Naja kaouthia \\
\hline 11 & & Muscarinic toxin-like protein 2 & P82463 & 4 & Naja kaouthia \\
\hline 12 & & Muscarinic toxin-like protein & Q9W727 & 1 & Bungarus multicinctus \\
\hline 13 & & Three-finger toxin precursor, partial & ADN67582 & 1 & Naja atra \\
\hline 14 & & Three-finger toxin precursor, partial & ADN67582 & 1 & Naja atra \\
\hline 15 & 3FTXs (cytotoxins) & Cytotoxin Vc-5 & Q9PS34 & 2 & Naja oxiana \\
\hline 16 & & Cytotoxin homolog & P14541 & 1 & Naja kaouthia \\
\hline 17 & & Cytotoxin homolog $5 \mathrm{~V}$ & Q9W716 & 1 & Naja atra \\
\hline 18 & & Cytotoxin SP15c & P60308 & 1 & Naja atra \\
\hline 19 & & Cytotoxin 8 & P86540 & 2 & Naja naja \\
\hline 20 & & Cytotoxin 1 & P01447 & 2 & Naja naja \\
\hline 21 & & Cardiotoxin 7a & Q91126 & 6 & Naja atra \\
\hline 22 & & Cardiotoxin $1 \mathrm{e}$ & AAA90960 & 2 & Naja atra \\
\hline 23 & Venom Complement $C_{3}$-like & Venom factor & AAX86641 & 1 & Austrelaps superbus \\
\hline 24 & & Cobra venom factor & Q91132 & 10 & Naja kaouthia \\
\hline 25 & & A.superbus venom factor 1 & Q0ZZJ6 & 1 & Austrelaps superbus \\
\hline 26 & & Cobra venom factor alpha chain & Q91132 & 1 & Naja kaouthia \\
\hline 27 & & Cobra venom factor 1 , partial & AXL96620 & 6 & Ahaetulla prasina \\
\hline 28 & & Cobra venom factor, partial & AWX67646 & 2 & Boiga irregularis \\
\hline 29 & & Ophiophagus venom factor & $\mathrm{I} 2 \mathrm{C} 090$ & 1 & Ophiophagus hannah \\
\hline 30 & Venom Kunitz-type family & Kunitz-type serine protease inhibitor & P20229 & 2 & Naja naja \\
\hline 31 & & BPTI/Kunitz domain-containing protein-like & XP_026546510 & 1 & Notechis scutatus \\
\hline 32 & & Kunitz/BPTI-like toxin & XP_026579467 & 1 & Pseudonaja textilis \\
\hline 33 & natriuretic peptide family & Natriuretic peptide PaNP-c precursor, partial & AAZ82822 & 1 & Pseudechis australis \\
\hline 34 & NGF-beta family & Venom nerve growth factor 2 & Q5YF89 & 5 & Naja sputatrix \\
\hline 35 & & Nerve growth factor, partial & AAR24530 & 1 & Bitis gabonica \\
\hline 36 & & Nerve growth factor & BAN82142 & 4 & Ovophis okinavensis \\
\hline 37 & & Venom nerve growth factor 2 & Q3HXX9 & 1 & Hoplocephalus stephensii \\
\hline
\end{tabular}


Table 3. Cont.

\begin{tabular}{|c|c|c|c|c|c|}
\hline S. No. & Protein Family & Protein & Accession Code & $\begin{array}{l}\text { Number of } \\
\text { Matched Peptides }\end{array}$ & $\begin{array}{l}\text { Homology with Protein from the } \\
\text { Venom of Snake Species }\end{array}$ \\
\hline 38 & ohanin/vespryn family. & Thaicobrin & P82885 & 1 & Naja kaouthia \\
\hline 39 & & venom PRY-SPRY domain-containing protein, partial & AHZ08803 & 1 & Micropechis ikaheca \\
\hline 40 & CRISP & Cysteine-rich venom protein natrin-1 & Q7T1K6 & 3 & Naja atra \\
\hline 42 & & Cysteine-rich venom protein ophanin & Q7ZT98 & 1 & Ophiophagus hannah \\
\hline 43 & & Cysteine-rich venom protein, partial & BAP39957 & 1 & Protobothrops flavoviridis \\
\hline 44 & & Cysteine-rich venom protein 2 & Q7ZZN8 & 1 & Naja atra \\
\hline 45 & Phosoholipase A2 & Acidic phospholipase A2 3 & P60045 & 1 & Naja sagittifera \\
\hline 46 & & Acidic phospholipase A2 2 & P00597 & 1 & Naja kaouthia \\
\hline 47 & & Phospholipase a 2 & CAA45372 & 3 & Naja naja \\
\hline 48 & & Neutral phospholipase A2 paradoxin-like beta chain & Q45Z46 & 2 & Oxyuranus microlepidotus \\
\hline 49 & & Phospholipase A2 & AHZ08810 & 1 & Micropechis ikaheca \\
\hline 50 & & Phospholipase A2 & AAA66029.1 & 1 & Naja naja \\
\hline 51 & & Acidic phospholipase A2 2 & P15445 & 1 & Naja naja \\
\hline 52 & & Acidic phospholipase A2 1 & P00596 & 6 & Naja kaouthia \\
\hline 53 & & Acidic phospholipase A2 1 & Q9W7J4 & 1 & Pseudonaja textilis \\
\hline 54 & & Basic phospholipase A2 T1-2 A chain & P84472 & 1 & Bungarus candidus \\
\hline 55 & & Acidic phospholipase A2 C & Q92086 & 11 & Naja sputatrix \\
\hline 56 & & Acidic phospholipase A2 1 & P00598 & 1 & Naja naja \\
\hline 57 & & Acidic phospholipase A2 beta-bungarotoxin A4 chain & P17934 & 1 & Bungarus multicinctus \\
\hline 59 & Phospholipase B & Phospholipase B, partial & AXL95274 & 1 & Spilotes sulphureus \\
\hline 60 & & Phospholipase B1, partial & AXL96606 & 2 & Ahaetulla prasina \\
\hline 61 & & Phospholipase B1, membrane-associated & $X P \_02653746$ & 1 & Notechis scutatus \\
\hline 62 & SVMP & Snake venom metalloproteinase & D3TTC2 & 4 & Naja atra \\
\hline 63 & & Snake venom metalloproteinase & F8RKW1 & 1 & Drysdalia coronoides \\
\hline 64 & & Snake venom metalloproteinase & Q9PVK7 & 1 & Naja kaouthia \\
\hline 65 & & $\begin{array}{l}\text { Disintegrin and metalloproteinase domain-containing } \\
\text { protein } 20 \text {, partial }\end{array}$ & ETE72945 & 1 & Ophiophagus hannah \\
\hline 66 & & $\begin{array}{l}\text { Disintegrin and metalloproteinase domain-containing } \\
\text { protein 21, partial }\end{array}$ & ETE71596 & 1 & Ophiophagus hannah \\
\hline 67 & & $\begin{array}{l}\text { disintegrin and metalloproteinase domain-containing } \\
\text { protein } 10-\text {-like, partial }\end{array}$ & XP_026580760 & 1 & Pseudonaja textilis \\
\hline 68 & & P-III snake venom metalloprotease, partial & AHZ08819 & 1 & Micropechis ikaheca \\
\hline 69 & & Zinc metalloproteinase-disintegrin-like kaouthiagin-like & D3TTC1 & 7 & Naja atra \\
\hline 70 & & Zinc metalloproteinase-disintegrin-like atrase-A & D5LMJ3 & 14 & Naja atra \\
\hline 71 & & $\begin{array}{l}\text { Hemorrhagic metalloproteinase-disintegrin- } \\
\text { like kaouthiagin }\end{array}$ & $\mathrm{P} 82942$ & 2 & Naja kaouthia \\
\hline 72 & & metalloproteinase 7 , partial & AXL96626 & 1 & Ahaetulla prasina \\
\hline
\end{tabular}


Table 3. Cont.

\begin{tabular}{|c|c|c|c|c|c|}
\hline S. No. & Protein Family & Protein & Accession Code & $\begin{array}{l}\text { Number of } \\
\text { Matched Peptides }\end{array}$ & $\begin{array}{l}\text { Homology with Protein from the } \\
\text { Venom of Snake Species }\end{array}$ \\
\hline 73 & & metalloproteinase, partial & AWX67576 & 1 & Boiga irregularis \\
\hline 74 & & $\begin{array}{l}\text { Snake venom metalloproteinase-disintegrin- } \\
\text { like mocarhagin }\end{array}$ & Q10749 & 3 & Naja mossambica \\
\hline 75 & & Snake venom metalloproteinase & Q9W6M5 & 1 & Deinagkistrodon acutus \\
\hline 76 & $\begin{array}{l}\text { Snake venom serine proteinase } \\
\text { (peptidase } \mathrm{S} 1 \text { family) }\end{array}$ & Tissue-type plasminogen activator, partial & ETE66683 & 3 & Ophiophagus hannah \\
\hline 77 & & tissue-type plasminogen activator, partial & XP_026544671 & 2 & Notechis scutatus \\
\hline 78 & & Snake venom serine protease 3 & $\mathrm{O} 13058$ & 1 & Protobothrops flavoviridis \\
\hline 79 & & Serine protease 27 , partial & ETE64653 & 1 & Ophiophagus hannah \\
\hline 81 & & Snake venom serine protease 3 & AAG10790 & 1 & Protobothrops jerdonii \\
\hline 82 & & Snake venom serine protease Dav-PA & Q9I8X1 & 1 & Deinagkistrodon acutus \\
\hline 83 & & serine protease 53 & XP_026576912 & 1 & Pseudonaja textilis \\
\hline 84 & 5'-nucleotidase family & $5^{\prime}$ nucleotidase, partial & AXL95273 & 1 & Spilotes sulphureus \\
\hline 85 & Aminopeptidase & aminopeptidase $\mathrm{N}$ isoform $\mathrm{X} 2$ & XP_026565037 & 4 & Pseudonaja textilis \\
\hline 86 & type-B carboxylesterase/lipase & acetylcholinesterase & XP_026549820 & 1 & Notechis scutatus \\
\hline 87 & Phosphodiesterase & Phosphodiesterase & BAN89425 & 2 & Ovophis okinavensis \\
\hline 88 & & Phosphodiesterase partial & ALA20853 & 1 & Macropisthodon rudis \\
\hline 89 & & Phosphodiesterase partial & AXL96599 & 1 & Borikenophis portoricensis \\
\hline 91 & & Snake venom Phosphodiesterase & A0A2D0TC04 & 2 & Naja atra \\
\hline 92 & Flavin monoamine oxidase family & L-amino acid oxidase, partial & AVX27607 & 7 & Naja atra \\
\hline 93 & & L-amino-acid oxidase & XP_026538830 & 4 & Notechis scutatus \\
\hline 94 & & L-amino-acid oxidase & Q4JHE3 & 1 & Oxyuranus scutellatus scutellatus \\
\hline 95 & & L-amino-acid oxidase & Q4JHE1 & 1 & Pseudechis australis \\
\hline 96 & & L-amino-acid oxidase & A8QL58 & 1 & Naja atra \\
\hline 97 & True venom lectin family & C-type lectin Cal & P21963 & 1 & Crotalus atrox \\
\hline 98 & Glutathione peroxidase & Glutathione peroxidase 3, partial & ETE68810 & 1 & Ophiophagus hannah \\
\hline 99 & & Glutathione peroxidase 3 isoform $\mathrm{X} 1$ & XP_026541908 & 1 & Notechis scutatus \\
\hline 100 & & Glutathione peroxidase 3 isoform $\mathrm{X} 1$ & XP_026552406 & 1 & Pseudonaja textilis \\
\hline
\end{tabular}


Table 3. Cont

\begin{tabular}{|c|c|c|c|c|c|}
\hline S. No. & Protein Family & Protein & Accession Code & $\begin{array}{l}\text { Number of } \\
\text { Matched Peptides }\end{array}$ & $\begin{array}{l}\text { Homology with Protein from the } \\
\text { Venom of Snake Species }\end{array}$ \\
\hline 101 & Leucine repeat & $\begin{array}{l}\text { Leucine-rich repeat and death domain-containing } \\
\text { protein } 1\end{array}$ & XP_026543987 & 1 & Notechis scutatus \\
\hline 102 & TNF receptor superfamily & Tumor necrosis factor receptor superfamily member $11 \mathrm{~B}$ & XP_026545353 & 1 & Notechis scutatus \\
\hline 103 & & Tumor necrosis factor receptor superfamily member $11 \mathrm{~B}$ & XP_026559377 & 1 & Pseudonaja textilis \\
\hline 104 & & Tumor necrosis factor receptor superfamily member 11B & ETE67452 & 1 & Ophiophagus hannah \\
\hline 105 & Intermediate filament family & Keratin, type II cytoskeletal 1, partia & ETE67131 & 1 & Ophiophagus hannah \\
\hline 106 & & Keratin, type II cytoskeletal 4 -like & XP_026539658 & 1 & Notechis scutatus \\
\hline 107 & & Keratin, type II cytoskeletal 5, partial & ETE59039 & 1 & Ophiophagus hannah \\
\hline 108 & & Keratin, type II cytoskeletal 5, partial & ETE59038 & 2 & Ophiophagus hannah \\
\hline 109 & & Keratin, type II cytoskeletal 1-like & XP_026573193 & 1 & Pseudonaja textilis \\
\hline 110 & & Keratin, type I cytoskeletal 19, partial & ETË70217 & 2 & Ophiophagus hannah \\
\hline 111 & & Keratin, type I cytoskeletal 18-like isoform X1 & XP_026521302 & 1 & Notechis scutatus \\
\hline 112 & Serpin Family & Serpin B5, partial & ETE65002 & 1 & Ophiophagus hannah \\
\hline 113 & Ankyrin repeat domain & M-phase phosphoprotein 8, partial & ETE73652 & 1 & Ophiophagus hannah \\
\hline 114 & Zinc finger containing proteins & Zinc finger protein, partial & ETE62318 & 1 & Ophiophagus hannah \\
\hline 115 & & Zinc finger protein, partial & ETE62303 & 1 & Ophiophagus hannah \\
\hline 116 & & Zinc finger protein $804 \mathrm{~A}$ & XP_026552505 & 1 & Pseudonaja textilis \\
\hline 117 & & Zinc finger SWIM domain-containing protein 6 & XP_026572863 & 1 & Pseudonaja textilis \\
\hline 118 & & Zinc finger MYM-type protein 2 isoform X1 & XP_026564670 & 1 & Pseudonaja textilis \\
\hline 120 & NHS Family & NHS-like protein 1 isoform X1 & XP_026561348 & 1 & Pseudonaja textilis \\
\hline 121 & Protein family not assigned & Holliday junction recognition protein & XP_026519764 & 1 & Notechis scutatus \\
\hline 122 & & $\mathrm{~N}$-acetylgalactosaminyltransferase 7 isoform $\mathrm{X} 1$ & XP_026555474 & 1 & Pseudonaja textilis \\
\hline 123 & & PHD finger protein 3 & XP_026520899 & 1 & Notechis scutatus \\
\hline 124 & & Sulfhydryl oxidase 1 (contains FAD binding domain) & ETE70041 & 1 & Ophiophagus hannah \\
\hline 125 & & C-C chemokine receptor type 10 , partial & ETE65216 & 1 & Ophiophagus hannah \\
\hline 126 & & Cytosolic carboxypeptidase 2 & XP_026521145 & 1 & Notechis scutatus \\
\hline 127 & & SUMO-specific isopeptidase USPL1 isoform X1 & XP_026564646 & 1 & Pseudonaja textilis \\
\hline 128 & & Protein VPRBP & ETE70381 & 1 & Ophiophagus hannah \\
\hline 129 & & Cilia- and flagella-associated protein 97 & XP_026553667 & 1 & Pseudonaja textilis \\
\hline 130 & & lpxK, partial & ETE68446 & 1 & Ophiophagus hannah \\
\hline 131 & & Zinc phosphodiesterase ELAC protein 2, partial & ETE70777 & 1 & Ophiophagus hannah \\
\hline 132 & & NHS-like protein 1 isoform X1 & XP_026561348 & 1 & Pseudonaja textilis \\
\hline 133 & & Pro-cathepsin H & XP_026565144 & 1 & Pseudonaja textilis \\
\hline 134 & & C4b-binding protein alpha chain-like isoform X1 & XP_026571379 & 1 & Pseudonaja textilis \\
\hline 135 & & $\begin{array}{l}\text { Janus kinase and microtubule-interacting protein } 3 \\
\text { isoform } X 1\end{array}$ & XP_026566312 & 1 & Pseudonaja textilis \\
\hline
\end{tabular}


Table 3. Cont.

\begin{tabular}{|c|c|c|c|c|c|}
\hline S. No. & Protein Family & Protein & Accession Code & $\begin{array}{l}\text { Number of } \\
\text { Matched Peptides }\end{array}$ & $\begin{array}{l}\text { Homology with Protein from the } \\
\text { Venom of Snake Species }\end{array}$ \\
\hline 136 & & WD and tetratricopeptide repeats protein 1 & XP_026558310 & 1 & Pseudonaja textilis \\
\hline 137 & & Pro-cathepsin $\mathrm{H}$ & XP_026565144 & 1 & Pseudonaja textilis \\
\hline 138 & & C4b-binding protein alpha chain-like isoform $\mathrm{X} 1$ & XP_026571379 & 1 & Pseudonaja textilis \\
\hline 140 & & WD and tetratricopeptide repeats protein 1 & XP_026558310 & 1 & Pseudonaja textilis \\
\hline
\end{tabular}

The bold text indicates the proteins identified to have $\mathrm{N}$-terminal acetylation. 
A comparative summary of the protein families of the two venoms is presented in Table 1. Figure 3, presents a comparison of the relative abundance of different venom protein families as pie charts. From the pie charts, it can be observed that there are significant differences in the proteome of two snake venoms. In the venom of N. naja, three-finger toxins (3FTx) are more abundant, while in N. oxiana venom, both 3FTXs and snake venom metalloproteinase (SVMPs) are almost equally abundant. In NO, snake venom serine proteases (SVSPs) and phospholipase $\mathrm{A}_{2}\left(\mathrm{PLA}_{2} \mathrm{~s}\right)$ are much more abundant than in NN. There are other subtle variations in the relative abundance of protein families between the two venoms. For example, Cysteine-rich Secretory Protein (CRISP) family is much more abundant in NN as compared to NO. Further, NN venom contains 11 protein families, which could not be found in $\mathrm{NO}$ venom, listed in Table 1 and highlighted in red color. Whereas NO venom contains serpins, which are absent in NN venom. Figure 3 shows that NN venom is much more versatile and contains a number of different proteins (Table 1). Data base searches revealed that our data provide a deeper insight of the NN and NO venom proteomes. There are several protein families, which have not been reported earlier in NN venom, including western and eastern Indian N. naja. In Table 1, the protein families discovered and reported for the first time in terms of our investigations are shown with check mark $(\checkmark)$. Interestingly previous studies reported $\mathrm{PLA}_{2}$ as the second most abundant protein family found in N. naja venom, and that SVMP was present in relatively low abundance [8,42-46]. In contrast, our data showed SVMP as the second most abundant protein family in N. naja. The venom proteome of N. oxiana displays that, both 3FTXs and SVMP are equally abundant like that of king cobra (Ophiophagus hannah) [51], as illustrated in Figure 3A.
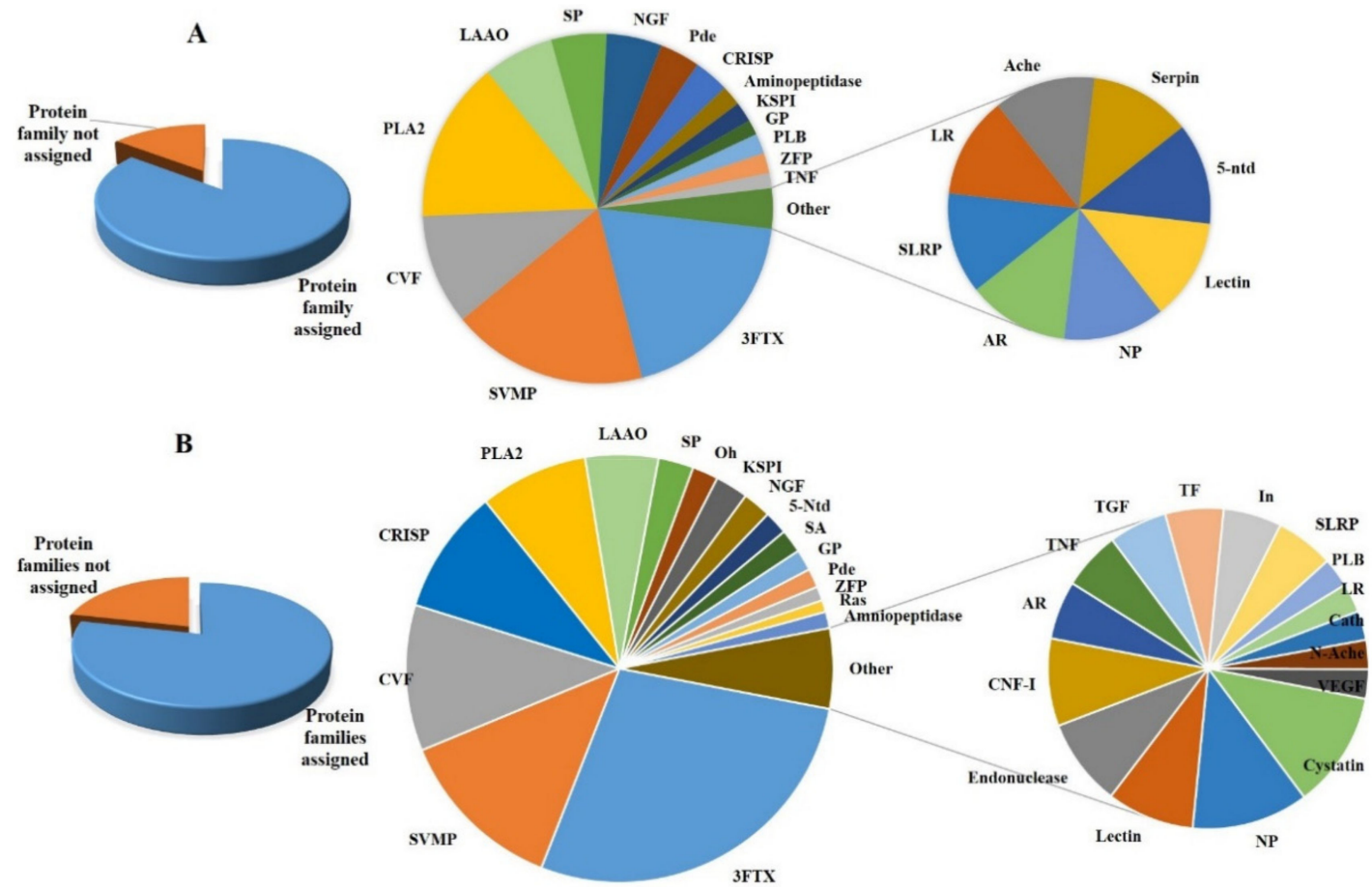

Figure 3. Pie chart illustrations highlighting the relative abundance of various protein families in the two venoms. (A) N. oxiana (B) N. naja.

In the present work, three types of posttranslational modification were also observed, i.e., $\mathrm{N}$-terminus pyro-glutamate, methionine oxidation and $\mathrm{N}$-terminal acetylation ( $\mathrm{N}$-ace). Pyro-glutamate posttranslational modifications of the venom proteins has been described before and are known to confer stability to the proteins and peptides [52-55]. However, modification of methionine residues and pyro-glutamate cannot be excluded during sample preparation. Therefore, keeping in view this possibility we have not discussed the observed methionine and pyro-glutamate modifications. The current study is the first description of $\mathrm{N}$-terminal acetylation of venom proteins. In N. naja venom 
we were able to identify three peptide fragments (Muscarinic toxin-like protein 3, Acid phospholipase $\mathrm{A}_{2}$ and weak neurotoxin 7) containing $\mathrm{N}$-ace modification. Whereas in N. oxiana one peptide (Muscarinic toxin-like protein 3) was identified with $\mathrm{N}$-ace. These sequences have been highlighted with green colour in Supplementary Tables S1 and S2.

In the present work, we have identified a number of proteins like cobra serum albumin, leucine repeat, zinc finger containing protein, venom lectin protein, Ras-like protein. The presence of Ras-like protein demonstrates the presence of extracellular vesicles in the venom of Naja naja. The comparison of our proteomic data with that of N. naja snake both from western and eastern India, reveals that such proteins were not identified in Indian N. naja, Further in Pakistani Naja naja snake we not could identify cholinesterase, butyrylcholinesterase, hyalurinidase and snaclec proteins which were previously reported in Indian N. naja venom [45,46].

Below we briefly describe and discuss the different venom protein families identified.

\section{Discussion}

\subsection{Major Protein Components (Relative Abundance >2\%)}

\subsubsection{Three-Finger Toxins}

The detailed proteomic investigations of the, $\mathrm{NN}$ and $\mathrm{NO}$ snake venoms identified two main types of three-finger toxins, i.e., neurotoxins and cytotoxins. The venom of $\mathrm{NN}$ consists of an overall higher abundance and a greater diversity of 3FTXs, as compared to NO (Tables 1 and 2, Figure 3). Neurotoxins are predominant in both venoms, as compared to cytotoxins, Figure 4 . Among the neurotoxins, long, muscarinic, weak, 3FTxs precursor and aminergic toxin families are present in both venoms. In case of $\mathrm{NO}$, a rather low amount of long neurotoxin is present, represented by one neurotoxin, cobratoxin. Whereas, long neurotoxins constitute a major proportion of neurotoxins found in the NN venom. Figure 4 indicates that in $\mathrm{NO}$ venom, muscarinic toxins are present in relatively higher amounts as compared to NN venom. It is interesting to note that $\mathrm{NN}$ venom contains an aminergic neurotoxin with homology to Dendroaspis angusticeps venom toxin AdTx1. This toxin is known to impair G-protein-coupled receptors $[56,57]$.

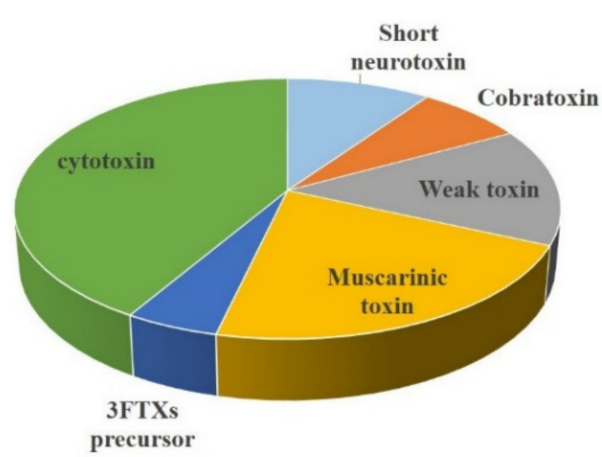

A

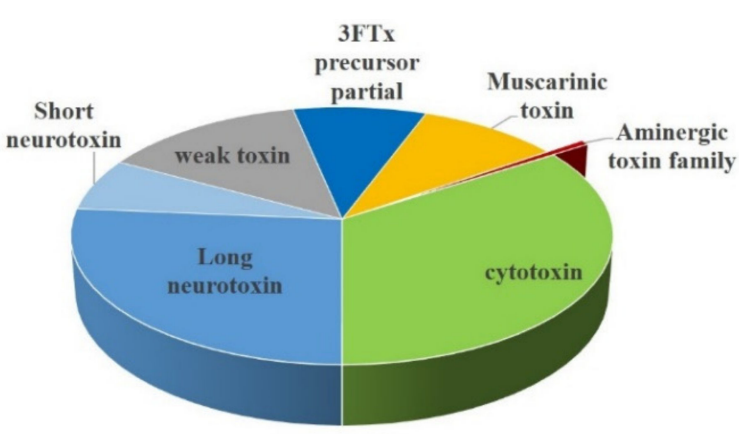

B

Figure 4. Pie chart illustrating a comparative profile of the three-finger toxins present in the two snake venoms. (A) N. oxiana (B) N. naja.

Previous studies have shown that 3FTXs make up approximately $56-84 \%$ of venom proteome in various species of Naja [58]. However, our results of Pakistani Naja venom samples show a much lower percentage of 3FTXS as compared to other investigations, which is $21 \%$ in NN and $16 \%$ in NO of the total venom proteins. In contrast to Pakistani N. naja venom proteome, the eastern Indian N. naja venom comprises of $61 \% 3 \mathrm{FTX}$ and western Indian N. naja contains $68 \%$ 3FTXs. Interestingly eastern Indian N. naja lacks short neurotoxins, which are present in both western Indian and Pakistani N. naja snake venom $[45,46]$. 
Investigating 3FTXs are not only of interest to characterize their toxicity, but also of great significance for structural studies, as well as for biotechnological, biomedical and evolutionary studies [59-63]. Already, 3FTXs have proven to be an efficient tool to analyze various receptor types, and to study diseases like Parkinson's disease, myasthenia gravis and cancer [64-71]. The aminergic toxins from mamba venom served as good candidates for protein resurrection methodology [72].

\subsubsection{Phospholipase $A_{2}$}

Both Naja snake venom contain PLA 2 . The percentage abundance of $\mathrm{PLA}_{2}$ enzymes $(12.6 \%)$ is higher in $\mathrm{NO}$ as compared to NN. $\mathrm{PLA}_{2} \mathrm{~s}$ make up $6 \%$ of the venom of $\mathrm{NN}$ (Table 1 ). A recent study reported the comparative enzymatic activity of $\mathrm{PLA}_{2} \mathrm{~s}$ in ten different Naja species, with highest activity in N. siamensis and lowest in N. nivea [73]. The venom proteome study of Indian N. naja venom carried out by A. K. Mukherjee research group reported that Indian N. naja contains 20-27\% PLA 2 S [45,46]. This is much higher than the amount of PLA2s present in Pakistani N. naja. A proteomic study of N. kaouthia venom reported $\mathrm{PLA}_{2} \mathrm{~S}$ as one of the most abundant venom proteins [74]. While another study on the venom proteome of $N$. annulifera did not detect $\mathrm{PLA}_{2} \mathrm{~s}$ [75]. In the venom of $N$. philippinensis $\mathrm{PLA}_{2} \mathrm{~s}$ made up $22.88 \%$ of venom proteome [76]. Another study showed distinct distribution of PLA2s in Afro-Asian cobra venom. Asian spitting cobras showed highest $\mathrm{PLA}_{2}$ activity. Asian non-spitting and African spitting cobras showed moderate activity and low activity was shown by African non-spiting cobras [77].

Table 3 shows that both venom comprise of acidic and basic $\mathrm{PLA}_{2} \mathrm{~s}$. However, acidic $\mathrm{PLA}_{2} \mathrm{~s}$ are more abundant in the two venoms. Two fragments of phospholipases from NO bear homology to neutral $\mathrm{PLA}_{2} \mathrm{~s}$ paradoxin-like beta chain from Oxyuranus microlepidotus. This protein was found to be one of the most potent presynaptic neurotoxins [78]. Eleven peptide fragments bearing homology to acidic phospholipase in the venom of Naja sputatrix were identified (Table 3). In the Naja naja peptide fragments having homology to acidic $\mathrm{PLA}_{2} \mathrm{~S}$ from the venom of other Naja species were determined (Table 2). Six peptide fragments showed homology to acidic PLA $\mathrm{A}_{2}$ from the venom of Pseudonaja textilis. A previous study reported this molecule to have moderate enzymatic activity and procoagulant property and was found to be non-lethal [79]. In the NN venom two peptide fragments matching Basic phospholipase A2 from Bungarus candidus venom and one matching with basic $\mathrm{PLA}_{2}$ with sea krait was identified. While in NO venom only one peptide fragment having homology to a basic PLA 2 from Bungarus candidus was found. The activity and specificity of basic phospholipases from Agkistrodon h. blomhiffii and Pakistani N. naja was studied on intact human erythrocytes. Although belonging to two different snake families, similar response was reported for these molecules, from both venoms. Basic PLA 2 induced the hydrolysis of membrane phospholipids and total cell hemolysis [80]. Despite the fact that acidic $\mathrm{PLA}_{2} \mathrm{~S}$ are found abundantly in the snake venom, their role is poorly understood [81]. In spite of having high catalytic activity as compared to basic $\mathrm{PLA}_{2} \mathrm{~s}$, they do not induce toxicity [82]. Studies have suggested acidic $\mathrm{PLA}_{2} \mathrm{~s}$ to participate in prey digestion [83]. Other studies have suggested that acidic $\mathrm{PLA}_{2} \mathrm{~S}$ work synergistically with other venom toxins, as $\mathrm{PLA}_{2} \mathrm{~s}$, metalloprotease and cytotoxins [84-86].

$\mathrm{PLA}_{2}$ is ubiquitously found in nature $[87,88]$. In mammals, they are known to play important and vital role in many life processes [89-91]. On the other hand, snake venom $\mathrm{PLA}_{2} \mathrm{~s}$ are toxic and interfere with a number of physiological processes, upon envenomation [87]. Phospholipase $A_{2}$ are also known to be responsible for the hepatic injury, inflammation and anticoagulation in a victim [26].

\subsubsection{Snake Venom Metalloproteinase}

The present study shows that N. naja and N. oxiana snake venom contain significant amounts of metalloproteinases, which are the second most abundant protein family. Proteomics study of other Naja species shows the presence of SVMPs in varying amounts ranging from as low as $0.9 \%$ to 16\% [74,92-100]. Previous proteomic studies reported a lower abundance of SVMP in Pakistani N. naja venom [42-44]. Three SVMPs bearing relatively higher homology with snake venom metalloproteinase 
from N. atra were determined in each of the two venoms. Twenty fragments of SVMPs were detected in N. naja venom, which are homologous to K-like SVMPs from N. atra. 13 Peptide fragments were found to match with SVMPs from N. kaouthia (Table 2). The data shows that in case of N. oxiana venom higher number of peptide fragments match with SVMPs from N. atra venom (Table 3). The eastern Indian N. naja contains only $6 \%$ SVMPs in contrast to Pakistani N. naja, which contains $10 \%$ of SVMPS. It is interesting to note that western Indian N. naja contains 16\% SVMPs as determined by A. K. Mukherjee and his research group $[45,46]$.

SVMPs are found in all advanced snakes and make up the major component of the venom of Crotalid and Viperid snakes [101-104]. SVMPs are structurally versatile and act on different hemostatic targets of prey upon envenomation [105]. These toxins provoke many systemic changes, such as hemorrhage, acute renal failure, coagulopathy, and/or platelet aggregation inhibition [106]. The SVMPs identified in terms of our investigations, in both of the venoms, belong to subfamily P-III. The P-III SVMPs possess gelatinolytic and hemorrhagic activities [105]. A previous study reported the hemorrhagic response of Pakistani N. naja venom in chicken egg [107]. The determination of a higher amount of SVMPs in both NO and NN venom indicates that there is potential for hemorrhage as a response of $\mathrm{NO}$ and NN snakebite envenomation.

\subsubsection{L-Amino Acid Oxidase}

Snake venom L-Amino acid oxidase (LAAOs) belong to the Flavin monoamine oxidase family and are dependent on FAD group for their activity. These proteins are present in both venoms studied and constitute approximately $4-5 \%$ of the venom proteome (Table 1 ). Peptide fragments bearing sequence similarity to LAAO from different snake venoms were detected and summarized (Tables 2 and 3). In contrast to our results, studies of western Indian N. naja venom report only 0.31\% LAAO. However, Indian N. naja venom contains 3\% LAAO, which is similar to that of Pakistani N. naja [45,46]. In terms of our investigations we identified that LAAO from both, NN and NO venom, have homology with LAAO from N. atra venom. LAAO is known to be prevalent in many snake venoms [108] but its role in snake venom envenomation pathology is not clear. A recent study reported that LAAO might contribute to severe tissue disruption. This study suggested that LAAO might elicit its toxicity by catalyzing the intracellular substrates [108]. Different biological activities of the isolated LAAO have been reported like, edema, cytotoxic, antibacterial, antiparasitic, and/or platelet aggregation effects $[109,110]$. Also some investigations reported antitumor effects of LAAO [111]. LAAO is a glycoprotein and glycosylation is also considered to play a significant role in the toxicity of LAAO, and cause cell death by interacting with the cell surface [112,113].

\subsubsection{Cobra Venom Factor}

Cobra venom factor (CVF) belong to the venom complement $\mathrm{C}_{3}$ homologue family. $\mathrm{CVF}$ constitutes approximately $9 \%$ of the total proteins identified in both venoms. The identified CVF peptides bear homology mainly to the CVFs from N. kaouthia. Fragments matching to CVF alpha chain and gamma chain were also analyzed. Peptide fragments showing sequence similarity to CVF proteins from other Elapidae and Colubridae have also been identified (Tables 2 and 3). Proteomic study of Indian N. naja venom showed that it contains only $0.03-1.7 \%$ CVF $[45,46]$, which is significantly less compared to our results obtained for the Pakistani N. naja. A venom proteome study of Naja philippinensis showed that it contains less than $4 \%$ [76]. The venom of N. ashei contains only $0.12 \%$ CVF [99]. Cobra venom factor is a complement activating protein and is functionally and structurally similar to complement component $\mathrm{C} 3 \mathrm{~b}$. It is a glycoprotein and herein glycosylation contributes in the immunogenicity of CVF [114,115]. In vivo studies have shown that CVF causes an acute inflammatory injury in the lungs [116]. CVF serves as a gold standard molecule for the evaluation of drugs for trials, to control diseases involving the complement system [117]. A recent study reported CVF as a promising candidate for the treatment of IRI-induced hepatic injury [118]. Our data reveals that CVF is one of the abundant 
proteins in the venom of Pakistani Naja naja and Naja oxiana (Figure 3). Therefore, these venom can be a good source of isolating CVF for use in biomedical research.

\subsubsection{Cysteine-Rich Secretory Protein}

Cysteine-rich secretory proteins (CRISPs) have been identified in many animal venoms. These proteins have two domains, a pathogenesis related domain at the N-terminal region and a cysteine rich domain at the C-terminus. Based on sequence homology the CRISP family is classified into four classes, and snake venom CRISPs belong to the group III [119]. CRISPs were found in much higher abundance in $N$. naja $(7 \%)$ as compared to $N$. oxiana $(2.8 \%)$ and peptide fragments showing similarities to CRISPs from different snake venoms were found in both venoms. However, highest similarity was found with the cysteine-rich venom protein natrin-1(NA-CRVP1) from N. atra. Investigations indicated that NA-CRVP1 could act as inflammatory modulator that could perturb the wound-healing process of a bitten victim by regulating the expression of adhesion molecules in endothelial cells. This study also showed that natrin contains a zinc-binding domain at the N-terminus and elicits its proinflammatory activity in a zinc and heparan-sulfate dependent manner [119]. Natrin has also been reported as a potassium channel blocker and in this context can weakly block muscle contraction [120-123]. In our study six peptide fragments matching CRISP from N. haje. A study reported this CRISP was found to be non-toxic when administered to crickets [124]. The venom proteome of $N$. haje contain 10\% CRISP [92]. Different species of Naja contain varying amounts of CRISP, from as low as $0.2 \%$ to $10 \%$ of the total venom proteome. The Indian N. naja contains $1.14-3 \%$ CRISPs $[45,46]$.

\subsubsection{Snake Venom Serine Proteinase}

Snake Venom Serine Proteinase (SVSPs) belong to the peptidase S1 family. N. oxiana venom proteome shows relatively higher abundance of serine proteinases (4\%) as compared to $N$. naja venom, which contains only $2 \%$ (Table 1 ; Figure 3 ). Both of the venoms contain peptide fragments, which bear homology to tissue-type plasminogen activators from Ophiophagus hannah and the thrombin-like enzyme TLP from Indian N. naja. In addition to this, peptide fragments having sequence similarity to SVSP have also been identified (Tables 2 and 3). SVSPs have been identified in only few Naja species venom. In western Indian N. naja the SVSPs contributed only $0.69 \%$ to venom proteome [46]. N. philippinensis venom proteome consists of $0.35 \%$ SVSPs [76]. Previous studies showed that SVSPS are absent in Eastern Indian N.naja venom, while a small percentage $(0.03 \%)$ was reported for the western Indian snake $[45,46]$.

SVSPs have high specificity towards their substrates. Based on their biological roles, they have also been classified as activators of the fibrinolytic system, procoagulant, anticoagulant and platelet-aggregating enzymes [125]. A few SVSPs, like ancrod and batroxobin have already applications in the treatment of cardiovascular problems, while reptilase serves today as a diagnostic probe for dysfibrinogenemia [126].

\subsubsection{Snake Venom Nerve Growth Factor}

Snake venom Nerve Growth Factor (NGF) were identified in both venoms but were relatively more abundant in the venom of N. oxiana (4\%) as compared to $N$. naja ( $2 \%)$, Table 3. In both venoms, peptides sharing homology with Ovophis okinavensis, N. sputatrix, and Bitis gabonica NGF were identified (Tables 1 and 2). In N. naja seven peptides bearing homology with Pseudechis australis were also identified. Further, additional peptide fragments of NGF were also identified in terms of our investigations (Tables 2 and 3). A previous proteomic study also showed Pakistani N. naja venom to contain $2 \%$ NGF [42]. N. naja snake venom from east India contained 3.1\% and $1 \%$ in western India sample. In the same study N. kaouthia from eastern India was shown to contain 1\% NGF [45,46]. N. philippinensis contain only $0.06 \%$ NGF [76]. Proteomic analysis of other Naja species venom have also shown them to 
contain NGF but their relative abundance was not calculated [93,100]. Moroccan cobra venom contains $5 \%$ NGF of total venom proteome [92].

Till now not much is known about the contribution and function of NGFs in envenomation. Various bioassays have shown that NGFs have neurotropic activity. Snake venom NGFs have been suggested as a pharmacological tool to study the structure function relationship of human trkA receptor [127]. Studies show that NGFs assert venom toxicity indirectly, either by acting as a carrier of other neurotoxins, which do not have specific recognition sites, like phospholipase or by inducing plasma extravasation at the site of snakebite. NGF is known to coexist with CVF in cobra snake venom, and might be responsible for enhancing the toxic mechanism of CVF in an indirect manner [128]. In 1986, two scientists were awarded a Nobel Prize for their pioneering work, which allowed to explain cell growth regulation. And in context of this investigations Cohen serendipitously discovered NGF from snake venom of Agkistrodon piscivorus [129].

\subsubsection{Snake Venom Phosphodiesterase}

A lower abundance of snake venom phosphodieterases (PDEs) was determined in both venoms, although relatively higher in N. oxiana, i.e., 3.1\%. N. naja venom contains only $1.1 \%$ of PDEs. Peptides fragments matching with PDEs from the venom of N. atra, Ovophis okinavensis, and Borikenophis portoricensis were identified in both venom. A recent study determined PDE activity in the venom of ten different species of Naja. All the species showed PDE activity with minor variation [73]. The Indian N. naja venom was reported to contain less than $1 \%$ PDEs, which is similar to Pakistani N. naja.

PDEs are ubiquitously present in snake venom but their activity is higher in Viperidae venom as compared to Elapidae family [130]. In recent years, there has been considerable interest in snake venom PDEs due to their potential applications as pharmacological tool and drug lead. The endonuclease activity of PDEs rendered their use in sequencing of polynucleotides and oligonucleotides [130]. Phosphoribosylation, a protein modification, can also be processed by PDEs [131]. Recent innovative approaches, have utilized snake venom PDEs to digest genomic DNA into single nucleosides to study modifications of DNA [132-134].

\subsection{Minor Protein Components (Relative Abundance $\leq 2 \%$ )}

A large number of low abundant proteins were found in both venoms, particularly in N. naja (Tables 2 and 3). Ras-like proteins, identified in the venom of N. naja were of particular interest, as they indicate the presence of extra0cellular vesicles in the venom. Snake venom extracellular vesicles (SVEVs) have previously been isolated from the venom of Agkistrodon contortrix contortrix, Crotalus atrox, Crotalus viridis, and Crotalus cerberus oreganus. The size distribution of SVEVs was found to be between approximately 50-500 $\mathrm{nm}$. Proteomic investigations revealed that SVEVs could be assigned to eight different protein classes, such as SVMP, SVSP, and disintegrins [135].

Exosome-like vesicles have also been reported in the venom of Gloydius blomhoffii blomhoffii [136]. In this context extracellular vesicles (EV) are known to carry a diverse cargo of molecules as proteins, DNA, RNA, and/or lipids [137]. Further, EVs are involved in cell-to-cell communication, immune response and apoptotic rescue [138,139] and participate in the maintenance of normal as well as pathophysiological conditions, like cancer [140-142]. The proteomic study of extracellular vesicles released from cancer cells have shown the presence of Ras proteins functioning as biomarkers for extracellular vesicles [137,143-145]. Studies have shown that Ras proteins are involved in the regulation and assembly of extracellular vesicles cargo [145-148]. Therefore, the identification of Ras-like proteins indicates the presence of extracellular vesicles in the venom of $N$. naja. However direct experimental work needs to be done to confirm the presence of such vesicles in the venom. SVEVs in the venom may be involved in another mechanism to secrete membrane proteins like aminopeptidase A and G coupled receptors. SVEVs may also offer an additional route for the envenomation process, thereby facilitating toxins to translocate inside the prey cells. 
In the present work, a number of proteins have been identified for the first time in the proteome of these venoms, like G-protein coupled receptors, zinc finger proteins, ankyrin repeat, leucine repeat, Ubiquitin carboxyl-terminal hydrolase and a number of other protein. It can be assumed that these proteins have also a function in the venom. Ankyrin repeats and zinc finger proteins were also identified recently, in the venom of King cobra, Naja annulifera and Micrurus pyrrhocryptus [51,100,149]. A rather old publication reported cobra serum albumin in the venom of cobra snakes [150]. Our data also revealed the presence of cobra serum albumin in the venom of $N$. naja. It is possible that upon envenomation cobra serum albumin is responsible or supporting the transportation of other venom proteins in the prey serum. Previous studies have reported Cobra blood serum albumin as an antitoxic protein, having the potential to sequester endogenous toxins [151,152]. Cobra serum albumin was also reported in the venom proteome of N. sumatrana [93]. Further, we identified glutathione peroxidase in both venoms. A recent proteomic study also reported the presence of glutathione peroxidase in the venom of Micrurus pyrrhocryptus and N. annulifera $[100,149]$. It can be speculated that this protein might be involved in protecting the venom gland from oxidative damage. Phospholipase $\mathrm{A}_{2}$ inhibitors, bearing similarity to $\mathrm{PLA}_{2}$ inhibitor isolated from the serum of Elaphe quadrivirgata and Naja kaouthia snakes, were identified in the venom of N. naja. This inhibitor was shown to inhibit the enzymatic activity of all till now known PLA 2 enzymes [153,154]. Phospholipase B was also identified in both venom. Only $0.1 \%$ constituted the venom proteome of NN while that of NO contained $1.6 \%$ of the total venom proteome. Studies have shown that PLBs make up approximately $0.34 \%$ of venom components, and in Viperidae venom it varies between $0.23 \%$ to $2.5 \%$ [155]. Insulin and Transferrin proteins were also identified in the venom of N. naja. Transferrin is a metal binding proteins. Transferrin was also reported before in the venom of $P$. australis, utilizing two dimensional gel electrophoresis [156]. Snake venom VEGF bearing similarities to that isolated also in Bitis arietans venom, identified in N. naja venom as well. Studies have shown that different variants of snake venom VEGF induce angiogenesis and vascular permeability through different mechanisms [157,158]. Snake venom VEGF are potential candidates for therapeutic angiogenesis [159]. A low abundance of Kunitz type serine protease inhibitors (KSPI) was identified in the venom of both snakes. Snake venom KSPI have the potential to selective inhibit distinct serine proteases [35]. Some of the snake venom KSPI have evolved as potassium channel blockers [160]. BF9 a snake venom KSPI, which act as potassium channel blockers and retain the serine protease inhibitory activity. This bifunctional KSPI was reported in the venom of Bungarus fasciatus [161]. Interestingly another type of serine protease inhibitor, i.e., serpin, was identified in the venom of N. oxiana. Proteins belonging to Ohanin/Vespryn family were found in both venoms. They are small proteins with an average mass of approx. $12 \mathrm{kDa}$, and are neurotoxic in nature [162]. Further, we could identify $5^{\prime}$-nucleotidase in both venoms. This family of protein is found in different snake venoms [163]. These enzymes play a major role in the release of adenosine upon envenomation, which facilitates prey immobilization. In vivo studies have shown that 5-nucleotidases act synergistically with other venom components like phospholipases, disintegrins to exert a pronounced anticoagulant effect [164]. Aminopeptidase was identified in both N. naja and N. oxiana venoms. Aminopeptidase A activity has been found in the venoms of snakes belonging to Elapidae and Viperidae families. Till now not much is known about the contribution of this enzymes within envenomation pathology [165]. Cystatin, having similarity to cystatin from the venom of N. kaouthia, was identified for the first time in the venom of N. naja in the present study. Cystatin is a cysteine protease inhibitor [166]. Natriuretic peptides were identified in both N. naja and N. oxiana venom. These peptides are known to induce hypotension upon envenomation $[167,168]$. Cathelicidin was identified in the venom of $N$. naja, and previous studies have shown it to be potent antimicrobial peptide [169].

\subsection{Posttranslational Modifications}

In terms of our investigations, we were able to identify $\mathrm{N}$-terminal acetylation (N-ace) for the first time in the snake venom. This posttranslational modification is known to carry and support out different 
functions in the cell. A most analyzed function of $\mathrm{N}$-ace is the regulation of protein half-life, by labelling proteins for polyubiquitation and thus degradation by the proteasome [170,171]. N-ace modification plays a role in protein folding and protein complex formation [172,173]. Furthermore, studies have shown that $\mathrm{N}$-ace modification mediates the interaction of proteins with membrane and subcellular localization [173]. A probable role of this modification in snake venom proteins could be to stabilize them against proteolytic cleavage, and to assist in distinct protein-protein interactions upon envenomation. In both venoms a peptide fragment bearing homology to muscarinic toxin like-protein 3, from the venom of Naja kaouthia was found to be $\mathrm{N}$ - terminal acetylated. Whereas in Naja naja two other peptide fragments were identified to be $\mathrm{N}$-terminal acetylated. One bearing homology to phospholipase $\mathrm{A}_{2}$ and other to a weak neurotoxin 7 (Supplementary Table S1 and S2).

\section{Conclusions}

Using the MS shotgun approach we could provide a holistic view of the venom profile of the two Pakistani cobra snakes N. naja and N. oxiana. Our data shows for the first time the venom proteome of N. oxiana. The comparative evaluation of the venom proteome of the two snakes reveals differences, as well as similarities in their venom composition. Both snake venoms contain different types of three-finger toxins in their venom, although they exit sympatrically. There are a few toxin families, which were only found in the venom of N. naja, like cystatin, VEGF, TGF, BPP, and Cathelicidin. Therefore, we can suggest, that venom samples from both species should be utilized for the production of effective antivenoms. Also, applying state-of-the-art mass spectrometric tools allowed to identify a number of proteins not known before to be in these venoms, like Ras-GTPase, Ankyrin repeats, leucine repeat, G-protein coupled receptor, zinc finger protein, holiday junction protein, and endonuclease. In this context, identification of Ras-like proteins provided a clue about the presence of extracellular vesicles. These vesicles might function as an additional carrier to transport venom components in the prey upon envenomation. Further, our data highlight $\mathrm{N}$-terminal acetylation of venom proteins for the first time and the results delineate the unique complexity of snake venoms, and open routes for further research to understand function of these molecules upon envenomation.

\section{Materials and Methods}

\subsection{Venom Collection}

Venom was milked manually from adult snake species of N. naja (black cobra/Indian cobra/ Spectacled cobra) and N. oxiana (brown cobra/Caspian cobra/Central Asian cobra). For the proteomic studies of each species the venom was collected from three adult healthy snakes and pooled. The sex of the snakes was not determined. N. naja snakes were captured from the rural surroundings of Mianwali district, while N. oxiana snakes were caught from Lahore, Punjab province, Pakistan. The venom was freeze dried and kept at $-20^{\circ} \mathrm{C}$ till further use.

\subsection{Sample Preparation for LC-MS/MS}

For LC-MS/MS analysis the lyophilized crude venom from N. naja (black cobra) and N. oxiana (brown cobra) was dissolved in $10 \mathrm{mM}$ Triethylamonium bicarbonate (TEAB, Thermo Fisher Scientific), $1 \% v / w$ Sodium deoxycholate (SDC, Sigma) buffer. Protein concentration was determined using a bicinchoninic acid protein assay (Pierce ${ }^{\mathrm{TM}}$ BCA Protein Assay Kit, Thermo Fisher Scientific) and $20 \mu \mathrm{g}$ of venom protein was tryptically digested. In brief, cysteine residues were reduced for $30 \mathrm{~min}$, in the presence of $10 \mathrm{mM}$ dithiothreitol (DTT, Sigma) at $60^{\circ} \mathrm{C}$ and alkylated for $30 \mathrm{~min}$, with $20 \mathrm{mM}$ iodoacetamide (IAA, Sigma) at $37^{\circ} \mathrm{C}$ in the dark. Thereafter, sequencing grade trypsin (Promega) was added in a protease/protein ratio of $1: 100$ at $37^{\circ} \mathrm{C}$ to hydrolyze venom proteins overnight. Enzymatic activity was quenched by addition of $1 \% v / v$ formic acid (FA, Fluka) and the SDC was precipitated by centrifugation at $16,000 \times g$ for $5 \mathrm{~min}$. The peptide containing supernatant was vacuum dried and reconstituted in $0.1 \%$ FA for LC-MS/MS analysis. 


\subsection{LC-MS/MS Analysis of the Digested Venom}

LC-MS/MS analysis of the venom samples was performed using a nano ACQUITY UPLC ${ }^{\circledR}$ System (Waters, Manchester, UK) coupled to a Hybrid-Quadrupole-Orbitrap mass spectrometer (Q Exactive ${ }^{\mathrm{TM}}$, Thermo Fisher Scientific). The LC system was equipped with a reversed phase chromatography (RPC) columns [ACQUITY UPLC ${ }^{\circledR}$ Symmetry C $18(180 \mu \mathrm{m}$ i.d $\times 20 \mathrm{~cm}, 5 \mu \mathrm{m}$ particle size, $100 \AA$ pore size, Waters, Manchester, UK) as trap column and a RPC separation column (ACQUITY UPLC ${ }^{\circledR}$ Peptide BEH C-18 $(75 \mu \mathrm{m}$ i.d $\times 20 \mathrm{~cm}, 1.7 \mu \mathrm{m}$ particle size, 170 Å pore size, Waters, Manchester, UK) as analytical column. RPC was used with a linear 60 min acetonitrile gradient from $2-30 \%$ for peptide separation. (Solvent A: 0.1\% FA in water; Solvent B: 0.1\% FA in acetonitrile; Flow rate of $250 \mathrm{~nL} / \mathrm{min}$ ).

MS/MS data acquisition was performed in data dependent mode for the 15 most abundant precursor ions. Precursor ions with charge stages between $2+$ and $5+$ were selected for fragmentation if they exceeded an intensity threshold of 100,000. For MS/MS spectra acquisition the set AGC-target was 100,000 with a maximal ion injection time of $50 \mathrm{~ms}$. Precursor ions were fragmented at a normalized collision energy (NCE) of 25 and the fragment ions were measured with a resolution of 17,500 at $200 \mathrm{~m} / \mathrm{z}$. To avoid redundant precursor sampling a dynamic exclusion was applied for $20 \mathrm{~s}$.

\subsection{Data Analysis}

For protein identification, the generated raw data were processed using the Proteome Discoverer ${ }^{\mathrm{TM}}$ Software 2.0.0.802. Database search was performed with the SEQUEST algorithm against an Ophiophagus hannah (txid:8665, King cobra) protein database (UniProt), since it represents the closest sequence database to the analyzed samples. Carbamidomethylation of cysteine was used as fixed modification. Furthermore, oxidation of methionine, conversion of glutamine to pyro-glutamic acid at peptide $\mathrm{N}$-termini, loss of $\mathrm{N}$-terminal methionine and the acetylation of protein $\mathrm{N}$-termini were considered as variable modifications. Precursor and fragment ion tolerance were set at $10 \mathrm{ppm}$ and $0.02 \mathrm{Da}$, respectively. Peptide-spectra matches with a maximum delta $\mathrm{Cn}$ of 0.05 were used by Percolator for FDR estimation.

Unidentified spectra were exported to a new mgf file and de novo sequencing was performed with Novor [174] via DenovoGUI 1.16.2 [175]. Modifications and allowed mass tolerances were identical to the database search approach. Hits with a Novor score above 80 were considered for a protein BLAST approach. Protein BLAST for the sequenced peptides was conducted with the NCBI BLAST $p$ algorithm (2.9.0+) with default settings against non-redundant protein sequences (nr) narrowed down to serpents (taxid: 8570). Alignments were chosen according to the max Score, the query coverage and if the homologous proteins were related to venom activity. With this information, a venom specific peptide database was created to support database searching for further analyses. Similarly, the data search was also performed against Serpents protein data base from UniProt.

The mass spectrometry proteomics data have been deposited to the ProteomeXchange Consortium via the PRIDE partner repository [176] with the dataset identifier PXD018726 and 10.6019/PXD018726.

Venom components were classified according to protein families and their relative abundances calculated as, reported previously [51]. Briefly, the proteins analyzed were sorted into different groups of protein families. The relative abundance of each family was calculated as percent of total number of venom proteins detected by the mass spectrometer. The mathematical relationship below was used to calculate the relative abundance of each protein group. Pie chart (Figure 3) and Table 1, presents the percentage relative abundance of proteins.

$$
\frac{\text { Number of proteins (protein family) }}{\text { Total venom proteins detected using LC }- \text { MS } / \text { MS }} \times 100
$$


Supplementary Materials: The following are available online at http://www.mdpi.com/2072-6651/12/11/669/s1 Table S1: De novo peptide sequencing Naja naja venom. Table S2: De novo peptide sequencing Naja oxiana venom. Table S3: Proteomic data of Naja naja venom searched against Serpents Uniprot protein data base. Table S4: Proteomic data of Naja naja venom searched against King cobra Uniprot protein data base. Table S5: Proteomic data of Naja oxiana venom searched against Serpents Uniprot protein data base. Table S6: Proteomic data of Naja oxiana venom searched against Serpents Uniprot protein data base.

Author Contributions: Conceptualization, A.M. and C.B.; methodology, H.S., B.D., and A.B.; Venom milking, Z.M.; software, H.S., A.M., B.D., and A.B.; validation, H.S., A.M., C.B., S.A.A., and B.D.; formal analysis, A.M., S.A.A., A.U., and A.A.; investigation, A.M., S.A.A., B.D., A.B., A.A., and A.U.; resources, C.B. and H.S.; data curation, A.M. and B.D.; writing-original draft preparation, A.M.; writing-review and editing, All co-authors; supervision, C.B.; project administration, A.M. and C.B.; All authors have read and agreed to the published version of the manuscript.

Funding: This work is in part supported by the Cluster of Excellence 'The Hamburg Centre for Ultrafast Imaging' of the Deutsche Forschungsgemeinschaft (DFG)-EXC 1074-project ID 194651731. A part of the project was supported by higher education commission (HEC), Pakistan, (NRPU/R\&D/HEC-No: 20-3891) and (HEC-No: 7709/Federal/ NRPU/R\&D/HEC/ 2017).

Acknowledgments: The authors acknowledge financial support by the Cluster of Excellence "Advanced Imaging of Matter" of the Deutsche Forschungsgemeinschaft (DFG)-EXC 2056-project ID 390715994 and BMBF via project 05K16GUA. AM would like to thank Patrick Spencer, (Centro de Biotecnologia, Instituto de Pesquisas Energéticas e Nucleares, Avenue Lineu Prestes 2242, São Paulo 05508-000, Brazil) for critically reviewing the manuscript.

Conflicts of Interest: The authors declare no conflict of interest.

\section{References}

1. Ali, W.; Javaid, A.; Hussain, A.; Bukhari, M.S. Diversity and habitat preferences of amphibians and reptiles in pakistan: A review. J. Asia Pac. Biodivers. 2018, 11, 173-187. [CrossRef]

2. Khan, M.S. A guide to the snakes of pakistan. In Frankfurt Contributions to Natural History; Chimaira: Frankfurt, Germany, 2002; Volume 16.

3. Wallach, V.; Kenneth, L.W.; Boundy, J. Snakes of the World. A Catalogue of Living and Extinct Species; CRC Press: Boca Raton, FL, USA, 2014.

4. Panagides, N.; Jackson, T.N.; Ikonomopoulou, M.P.; Arbuckle, K.; Pretzler, R.; Yang, D.C.; Ali, S.A.; Koludarov, I.; Dobson, J.; Sanker, B.; et al. How the cobra got its flesh-eating venom: Cytotoxicity as a defensive innovation and its co-evolution with hooding, aposematic marking, and spitting. Toxins 2017, 9, 103. [CrossRef]

5. Wuster, W. The cobras of the genus naja in india. Hamadryad 1998, 23, 15-32.

6. Wuster, W.; Thorpe, R.S. Asiatic cobras: Population systematics of the naja naja species complex (serpentes: Elapidae) in india and central asia. Herpetologica 1992, 48, 69-85.

7. Gutierrez, J.M.; Williams, D.; Fan, H.W.; Warrell, D.A. Snakebite envenoming from a global perspective: Towards an integrated approach. Toxicon 2010, 56, 1223-1235. [CrossRef]

8. Wong, K.Y.; Tan, C.H.; Tan, N.H. Venom and purified toxins of the spectacled cobra (naja naja) from pakistan: Insights into toxicity and antivenom neutralization. Am. J. Trop Med. Hyg. 2016, 94, 1392-1399. [CrossRef]

9. World Health Organization. Rabies and Envenomings-A Neglected Public Health Issue; World Health Organization: Geneva, Switzerland, 2007.

10. Gutierrez, J.M.; Burnouf, T.; Harrison, R.A.; Calvete, J.J.; Kuch, U.; Warrell, D.A.; Williams, D.J.; Global Snakebite, I. A multicomponent strategy to improve the availability of antivenom for treating snakebite envenoming. Bull. World Health Organ. 2014, 92, 526-532. [CrossRef]

11. Scheske, L.; Ruitenberg, J.; Bissumbhar, B. Needs and availability of snake antivenoms: Relevance and application of international guidelines. Int. J. Health Policy Manag. 2015, 4, 447-457. [CrossRef]

12. Khan, M.S. The snakebite problem in pakistan. Bull. Chic. Herp. Soc. 2014, 49, 165-167.

13. Khan, R. Treating snakebites, one snake at a time. Express Trib. 2019. Available online: https://tribune.com. pk/story/1926889/treating-snakebites-one-snake-time (accessed on 11 March 2019).

14. Ralph, R.; Sharma, S.K.; Faiz, M.A.; Ribeiro, I.; Rijal, S.; Chappuis, F.; Kuch, U. The timing is right to end snakebite deaths in south asia. BMJ 2019, 364, k5317. [CrossRef]

15. Faisal, T.; Tan, K.Y.; Sim, S.M.; Quraishi, N.; Tan, N.H.; Tan, C.H. Proteomics, functional characterization and antivenom neutralization of the venom of pakistani russell's viper (daboia russelii) from the wild. J. Proteom. 2018, 183, 1-13. [CrossRef] 
16. Hashmi, S.U.; Alvi, A.; Munir, I.; Perveen, M.; Fazal, A.; Jackson, T.N.W.; Ali, S.A. Functional venomics of the big-4 snakes of pakistan. Toxicon 2020, 179, 60-71. [CrossRef] [PubMed]

17. Mackessy, S.P. The field of reptile toxinology: Snakes, lizards, and their venoms. In Handbook of Venoms and Toxins of Reptiles; Mackessy, S.P., Taylor and Francis Group, Eds.; CRC Press: Boca Raton, FL, USA, 2009; pp. 3-23.

18. Daltry, J.C.; Ponnudurai, G.; Shin, C.K.; Tan, N.H.; Thorpe, R.S.; Wuster, W. Electrophoretic profiles and biological activities: Intraspecific variation in the venom of the malayan pit viper (calloselasma rhodostoma). Toxicon 1996, 34, 67-79. [CrossRef]

19. Alape-Giron, A.; Sanz, L.; Escolano, J.; Flores-Diaz, M.; Madrigal, M.; Sasa, M.; Calvete, J.J. Snake venomics of the lancehead pitviper bothrops asper: Geographic, individual, and ontogenetic variations. J. Proteome Res. 2008, 7, 3556-3571. [CrossRef]

20. Tan, K.Y.; Tan, C.H.; Fung, S.Y.; Tan, N.H. Venomics, lethality and neutralization of naja kaouthia (monocled cobra) venoms from three different geographical regions of southeast Asia. J. Proteom. 2015, 120, 105-125. [CrossRef]

21. Amorim, F.G.; Costa, T.R.; Baiwir, D.; De Pauw, E.; Quinton, L.; Sampaio, S.V. Proteopeptidomic, functional and immunoreactivity characterization of bothrops moojeni snake venom: Influence of snake gender on venom composition. Toxins 2018, 10, 177. [CrossRef]

22. Augusto-de-Oliveira, C.; Stuginski, D.R.; Kitano, E.S.; Andrade-Silva, D.; Liberato, T.; Fukushima, I.; Serrano, S.M.; Zelanis, A. Dynamic rearrangement in snake venom gland proteome: Insights into bothrops jararaca intraspecific venom variation. J. Proteome Res. 2016, 15, 3752-3762. [CrossRef] [PubMed]

23. Rex, C.J.; Mackessy, S.P. Venom composition of adult western diamondback rattlesnakes (crotalus atrox) maintained under controlled diet and environmental conditions shows only minor changes. Toxicon 2019, 164, 51-60. [CrossRef]

24. Mukherjee, A.K.; Maity, C.R. The composition of naja naja venom samples from three districts of west bengal, india. Comp. Biochem. Physiol. A Mol. Integr. Physiol. 1998, 119, 621-627. [CrossRef]

25. Quraishi, N.A.; Qureshi, H.I.; Simpson, I.D. A contextual approach to managing snake bite in pakistan: Snake bite treatment with particular reference to neurotoxieity and the ideal hospital snake bite kit. J. Pak. Med. Assoc. 2008, 58, 325-331.

26. Asad, M.H.; Murtaza, G.; Ubaid, M.; Durre, S.; Sajjad, A.; Mehmood, R.; Mahmood, Q.; Ansari, M.M.; Karim, S.; Mehmood, Z.; et al. Naja naja karachiensis envenomation: Biochemical parameters for cardiac, liver, and renal damage along with their neutralization by medicinal plants. BioMed Res. Int. 2014, 2014, 970540. [CrossRef]

27. Lomonte, B.; Calvete, J.J. Strategies in 'snake venomics' aiming at an integrative view of compositional, functional, and immunological characteristics of venoms. J. Venom. Anim Toxins Incl. Trop. Dis. 2017, 23, 26. [CrossRef]

28. Vonk, F.J.; Casewell, N.R.; Henkel, C.V.; Heimberg, A.M.; Jansen, H.J.; McCleary, R.J.; Kerkkamp, H.M.; Vos, R.A.; Guerreiro, I.; Calvete, J.J.; et al. The king cobra genome reveals dynamic gene evolution and adaptation in the snake venom system. Proc. Natl. Acad. Sci. USA 2013, 110, 20651-20656. [CrossRef]

29. Von Reumont, B.M. Studying smaller and neglected organisms in modern evolutionary venomics implementing rnaseq (transcriptomics)-a critical guide. Toxins 2018, 10, 292. [CrossRef]

30. Fry, B.G. From genome to "venome": Molecular origin and evolution of the snake venom proteome inferred from phylogenetic analysis of toxin sequences and related body proteins. Genome Res. 2005, 15, 403-420. [CrossRef] [PubMed]

31. Kerkkamp, H.M.; Kini, R.M.; Pospelov, A.S.; Vonk, F.J.; Henkel, C.V.; Richardson, M.K. Snake genome sequencing: Results and future prospects. Toxins 2016, 8, 360. [CrossRef]

32. Wiezel, G.A.; Shibao, P.Y.T.; Cologna, C.T.; Morandi Filho, R.; Ueira-Vieira, C.; De Pauw, E.; Quinton, L.; Arantes, E.C. In-depth venome of the brazilian rattlesnake crotalus durissus terrificus: An integrative approach combining its venom gland transcriptome and venom proteome. J. Proteom. Res. 2018, 17, 3941-3958. [CrossRef]

33. Rokyta, D.R.; Margres, M.J.; Calvin, K. Post-transcriptional mechanisms contribute little to phenotypic variation in snake venoms. G3 Bethesda 2015, 5, 2375-2382. [CrossRef] 
34. Melani, R.D.; Skinner, O.S.; Fornelli, L.; Domont, G.B.; Compton, P.D.; Kelleher, N.L. Mapping proteoforms and protein complexes from king cobra venom using both denaturing and native top-down proteomics. Mol. Cell Proteom. 2016, 15, 2423-2434. [CrossRef]

35. Munawar, A.; Ali, S.A.; Akrem, A.; Betzel, C. Snake venom peptides: Tools of biodiscovery. Toxins 2018, 10, 474. [CrossRef]

36. Simoes-Silva, R.; Alfonso, J.; Gomez, A.; Holanda, R.J.; Sobrinho, J.C.; Zaqueo, K.D.; Moreira-Dill, L.S.; Kayano, A.M.; Grabner, F.P.; da Silva, S.L.; et al. Snake venom, a natural library of new potential therapeutic molecules: Challenges and current perspectives. Curr. Pharm. Biotechnol. 2018, 19, 308-335. [CrossRef]

37. King, G.F. Venoms as a platform for human drugs: Translating toxins into therapeutics. Expert Opin. Biol. 2011, 11, 1469-1484. [CrossRef]

38. Koh, D.C.; Armugam, A.; Jeyaseelan, K. Snake venom components and their applications in biomedicine. Cell Mol. Life Sci. 2006, 63, 3030-3041. [CrossRef]

39. Ciolek, J.; Reinfrank, H.; Quinton, L.; Viengchareun, S.; Stura, E.A.; Vera, L.; Sigismeau, S.; Mouillac, B.; Orcel, H.; Peigneur, S.; et al. Green mamba peptide targets type-2 vasopressin receptor against polycystic kidney disease. Proc. Natl. Acad. Sci. USA 2017, 114, 7154-7159. [CrossRef]

40. Abdel-Ghani, L.M.; Rahmy, T.R.; Tawfik, M.M.; Kaziri, I.; Al-Obaidi, A.; Rowan, E.G.; Plevin, R.; Abdel-Rahman, M.A. Cytotoxicity of nubein6.8 peptide isolated from the snake venom of naja nubiae on melanoma and ovarian carcinoma cell lines. Toxicon 2019, 168, 22-31. [CrossRef]

41. Wuster, W. Taxonomic changes and toxinology: Systematic revisions of the asiatic cobras (naja naja species complex). Toxicon 1996, 34, 399-406. [CrossRef]

42. Asad, M.H.H.B.; McCleary, R.J.R.; Salafutdinov, I.; Alam, F.; Shah, H.S.; Bibi, S.; Ali, A.; Khalid, S.; Hasan, S.M.F.; Sabatier, J.M.; et al. Proteomics study of southern punjab pakistani cobra (naja naja: Formerly naja naja karachiensis) venom. Toxicol. Environ. Chem. 2019. Ahead of Print. [CrossRef]

43. Ali, S.A.; Yang, D.C.; Jackson, T.N.W.; Undheim, E.A.B.; Koludarov, I.; Wood, K.; Jones, A.; Hodgson, W.C.; McCarthy, S.; Ruder, T.; et al. Venom proteomic characterization and relative antivenom neutralization of two medically important pakistani elapid snakes (bungarus sindanus and naja naja). J. Proteom. 2013, 89, 15-23. [CrossRef]

44. Wong, K.Y.; Tan, C.H.; Tan, K.Y.; Quraishi, N.H.; Tan, N.H. Elucidating the biogeographical variation of the venom of naja naja (spectacled cobra) from pakistan through a venom-decomplexing proteomic study. J. Proteom. 2018, 175, 156-173. [CrossRef]

45. Chanda, A.; Patra, A.; Kalita, B.; Mukherjee, A.K. Proteomics analysis to compare the venom composition between naja naja and naja kaouthia from the same geographical location of eastern india: Correlation with pathophysiology of envenomation and immunological cross-reactivity towards commercial polyantivenom. Expert Rev. Proteom. 2018, 15, 949-961.

46. Chanda, A.; Kalita, B.; Patra, A.; Senevirathne, W.; Mukherjee, A.K. Proteomic analysis and antivenomics study of western india naja naja venom: Correlation between venom composition and clinical manifestations of cobra bite in this region. Expert Rev. Proteom. 2019, 16, 171-184. [CrossRef]

47. Chanda, A.; Mukherjee, A.K. Quantitative proteomics to reveal the composition of southern india spectacled cobra (naja naja) venom and its immunological cross-reactivity towards commercial antivenom. Int. J. Biol. Macromol. 2020, 160, 224-232. [CrossRef] [PubMed]

48. Tan, C.H.; Tan, K.Y.; Fung, S.Y.; Tan, N.H. Venom-gland transcriptome and venom proteome of the malaysian king cobra (ophiophagus hannah). Bmc Genom. 2015, 16, 687. [CrossRef]

49. Liu, W.; Xu, Y.; Li, Z.; Fan, J.; Yang, Y. Genome-wide mining of microsatellites in king cobra (ophiophagus hannah) and cross-species development of tetranucleotide ssr markers in chinese cobra (naja atra). Mol. Biol. Rep. 2019, 46, 6087-6098. [CrossRef]

50. Suryamohan, K.; Krishnankutty, S.P.; Guillory, J.; Jevit, M.; Schroder, M.S.; Wu, M.; Kuriakose, B.; Mathew, O.K.; Perumal, R.C.; Koludarov, I.; et al. The indian cobra reference genome and transcriptome enables comprehensive identification of venom toxins. Nat. Genet. 2020, 52, 106-117. [CrossRef]

51. Kunalan, S.; Othman, I.; Syed Hassan, S.; Hodgson, W.C. Proteomic characterization of two medically important malaysian snake venoms, calloselasma rhodostoma (malayan pit viper) and ophiophagus hannah (king cobra). Toxins 2018, 10, 434. [CrossRef]

52. Munawar, A.; Zahid, A.; Negm, A.; Akrem, A.; Spencer, P.; Betzel, C. Isolation and characterization of bradykinin potentiating peptides from agkistrodon bilineatus venom. Proteome Sci. 2016, 14, 1. [CrossRef] 
53. Munawar, A.; Trusch, M.; Georgieva, D.; Hildebrand, D.; Kwiatkowski, M.; Behnken, H.; Harder, S.; Arni, R.; Spencer, P.; Schluter, H.; et al. Elapid snake venom analyses show the specificity of the peptide composition at the level of genera naja and notechis. Toxins 2014, 6, 850-868. [CrossRef]

54. Munawar, A.; Trusch, M.; Georgieva, D.; Spencer, P.; Frochaux, V.; Harder, S.; Arni, R.K.; Duhalov, D.; Genov, N.; Schluter, H.; et al. Venom peptide analysis of vipera ammodytes meridionalis (viperinae) and bothrops jararacussu (crotalinae) demonstrates subfamily-specificity of the peptidome in the family viperidae. Mol. Biosyst. 2011, 7, 3298-3307. [CrossRef]

55. Moura-da-Silva, A.M.; Almeida, M.T.; Portes-Junior, J.A.; Nicolau, C.A.; Gomes-Neto, F.; Valente, R.H. Processing of snake venom metalloproteinases: Generation of toxin diversity and enzyme inactivation. Toxins 2016, 8, 183. [CrossRef]

56. Maiga, A.; Mourier, G.; Quinton, L.; Rouget, C.; Gales, C.; Denis, C.; Lluel, P.; Senard, J.M.; Palea, S.; Servent, D.; et al. G protein-coupled receptors, an unexploited animal toxin targets: Exploration of green mamba venom for novel drug candidates active against adrenoceptors. Toxicon 2012, 59, 487-496. [CrossRef]

57. Blanchet, G.; Collet, G.; Mourier, G.; Gilles, N.; Fruchart-Gaillard, C.; Marcon, E.; Servent, D. Polypharmacology profiles and phylogenetic analysis of three-finger toxins from mamba venom: Case of aminergic toxins. Biochimie 2014, 103, 109-117. [CrossRef]

58. Tasoulis, T.; Isbister, G.K. A review and database of snake venom proteomes. Toxins 2017, 9, 290. [CrossRef]

59. Tsetlin, V.I.; Karlsson, E.; Utkin Yu, N.; Pluzhnikov, K.A.; Arseniev, A.S.; Surin, A.M.; Kondakov, V.V.; Bystrov, V.F.; Ivanov, V.T.; Ovchinnikov Yu, A. Interaction surfaces of neurotoxins and acetylcholine receptor. Toxicon 1982, 20, 83-93. [CrossRef]

60. Kreienkamp, H.J.; Weise, C.; Raba, R.; Aaviksaar, A.; Hucho, F. Anionic subsites of the catalytic center of acetylcholinesterase from torpedo and from cobra venom. Proc. Natl. Acad Sci. USA 1991, 88, 6117-6121. [CrossRef] [PubMed]

61. Hucho, F.; Weise, C.; Kreienkamp, H.J.; Tsetlin, V.; Utkin, Y.; Machold, J. Mapping the functional topography of a receptor. Bioorg. Khim 1992, 18, 1319-1329. [PubMed]

62. Nickitenko, A.V.; Michailov, A.M.; Betzel, C.; Wilson, K.S. Three-dimensional structure of neurotoxin-1 from naja naja oxiana venom at 1.9 a resolution. Febs Lett. 1993, 320, 111-117. [CrossRef]

63. Kini, R.M.; Koh, C.Y. Snake venom three-finger toxins and their potential in drug development targeting cardiovascular diseases. Biochem. Pharm. 2020, 114105. [CrossRef]

64. Chang, C.C.; Lee, C.Y. Isolation of neurotoxins from the venom of bungarus multicinctus and their modes of neuromuscular blocking action. Arch. Int. Pharm. 1963, 144, 241-257.

65. Changeux, J.P.; Kasai, M.; Lee, C.Y. Use of a snake venom toxin to characterize the cholinergic receptor protein. Proc. Natl. Acad. Sci. USA 1970, 67, 1241-1247. [CrossRef]

66. Jerusalinsky, D.; Kornisiuk, E.; Alfaro, P.; Quillfeldt, J.; Ferreira, A.; Rial, V.E.; Duran, R.; Cervenansky, C. Muscarinic toxins: Novel pharmacological tools for the muscarinic cholinergic system. Toxicon 2000, 38, 747-761. [CrossRef]

67. Chu, N.S. Contribution of a snake venom toxin to myasthenia gravis: The discovery of alpha-bungarotoxin in taiwan. J. Hist. Neurosci. 2005, 14, 138-148. [CrossRef] [PubMed]

68. Xu, Y.L.; Kou, J.Q.; Wang, S.Z.; Chen, C.X.; Qin, Z.H. Neurotoxin from naja naja atra venom inhibits skin allograft rejection in rats. Int. Immunopharmacol. 2015, 28, 188-198. [CrossRef] [PubMed]

69. Kryukova, E.V.; Shelukhina, I.V.; Kolacheva, A.A.; Alieva, A.K.; Shadrina, M.I.; Slominsky, P.A.; Kasheverov, I.E.; Utkin, Y.N.; Ugrumov, M.V.; Tsetlin, V.I. Possible involvement of neuronal nicotinic acetylcholine receptors in compensatory brain mechanisms at early stages of parkinson's disease. Biomed. Khim 2017, 63, 241-247. [CrossRef]

70. Tsai, P.C.; Fu, Y.S.; Chang, L.S.; Lin, S.R. Cardiotoxin iii inhibits hepatocyte growth factor-induced epithelial-mesenchymal transition and suppresses invasion of mda-mb-231 cells. J. Biochem. Mol. Toxicol 2016, 30, 12-21. [CrossRef]

71. Ebrahim, K.; Vatanpour, H.; Zare, A.; Shirazi, F.H.; Nakhjavani, M. Anticancer activity a of caspian cobra (naja naja oxiana) snake venom in human cancer cell lines via induction of apoptosis. Iran J. Pharm Res. 2016, 15, 101-112.

72. Blanchet, G.; Alili, D.; Protte, A.; Upert, G.; Gilles, N.; Tepshi, L.; Stura, E.A.; Mourier, G.; Servent, D. Ancestral protein resurrection and engineering opportunities of the mamba aminergic toxins. Sci. Rep. 2017, 7, 2701. [CrossRef] 
73. Modahl, C.M.; Roointan, A.; Rogers, J.; Currier, K.; Mackessy, S.P. Interspecific and intraspecific venom enzymatic variation among cobras (naja sp. And ophiophagus hannah). Comp. Biochem Physiol. C Toxicol. Pharm. 2020, 232, 108743. [CrossRef]

74. Deka, A.; Gogoi, A.; Das, D.; Purkayastha, J.; Doley, R. Proteomics of naja kaouthia venom from north east india and assessment of indian polyvalent antivenom by third generation antivenomics. J. Proteom. 2019, 207, 103463. [CrossRef]

75. Tan, K.Y.; Wong, K.Y.; Tan, N.H.; Tan, C.H. Quantitative proteomics of naja annulifera (sub-saharan snouted cobra) venom and neutralization activities of two antivenoms in africa. Int. J. Biol. Macromol. 2020, 158, 605-616. [CrossRef]

76. Tan, C.H.; Wong, K.Y.; Chong, H.P.; Tan, N.H.; Tan, K.Y. Proteomic insights into short neurotoxin-driven, highly neurotoxic venom of philippine cobra (naja philippinensis) and toxicity correlation of cobra envenomation in asia. J. Proteom. 2019, 206, 103418. [CrossRef] [PubMed]

77. Tan, C.H.; Wong, K.Y.; Tan, N.H.; Ng, T.S.; Tan, K.Y. Distinctive distribution of secretory phospholipases a(2) in the venoms of afro-asian cobras (subgenus: Naja, afronaja, boulengerina and uraeus). Toxins 2019, 11, 116. [CrossRef] [PubMed]

78. Hodgson, W.C.; Dal Belo, C.A.; Rowan, E.G. The neuromuscular activity of paradoxin: A presynaptic neurotoxin from the venom of the inland taipan (oxyuranus microlepidotus). Neuropharmacology 2007, 52, 1229-1236. [CrossRef] [PubMed]

79. Armugam, A.; Gong, N.; Li, X.; Siew, P.Y.; Chai, S.C.; Nair, R.; Jeyaseelan, K. Group ib phospholipase a2 from pseudonaja textilis. Arch. Biochem. Biophys. 2004, 421, 10-20. [CrossRef] [PubMed]

80. Martin, J.K.; Luthra, M.G.; Wells, M.A.; Watts, R.P.; Hanahan, D.J. Phospholipase a2 as a probe of phospholipid distribution in erythrocyte membranes. Factors influencing the apparent specificity of the reaction. Biochemistry 1975, 14, 5400-5408. [CrossRef]

81. Vargas, L.J.; Londono, M.; Quintana, J.C.; Rua, C.; Segura, C.; Lomonte, B.; Nunez, V. An acidic phospholipase a(2) with antibacterial activity from porthidium nasutum snake venom. Comp. Biochem Physiol. B Biochem. Mol. Biol. 2012, 161, 341-347. [CrossRef]

82. Marques, P.P.; Esteves, A.; Lancellotti, M.; Ponce-Soto, L.A.; Marangoni, S. Novel acidic phospholipase a2 from porthidium hyoprora causes inflammation with mast cell rich infiltrate. Biochem. Biophys. Rep. 2015, 1, 78-84. [CrossRef]

83. Fernandez, J.; Gutierrez, J.M.; Angulo, Y.; Sanz, L.; Juarez, P.; Calvete, J.J.; Lomonte, B. Isolation of an acidic phospholipase a2 from the venom of the snake bothrops asper of costa rica: Biochemical and toxicological characterization. Biochimie 2010, 92, 273-283. [CrossRef]

84. Mora-Obando, D.; Fernandez, J.; Montecucco, C.; Gutierrez, J.M.; Lomonte, B. Synergism between basic asp49 and lys49 phospholipase a2 myotoxins of viperid snake venom in vitro and in vivo. PLoS ONE 2014, 9, e109846. [CrossRef]

85. Laustsen, A.H. Toxin synergism in snake venoms. J. Toxin Rev. 2016, 35, 165-170. [CrossRef]

86. Jimenez-Charris, E.; Montealegre-Sanchez, L.; Solano-Redondo, L.; Castro-Herrera, F.; Fierro-Perez, L.; Lomonte, B. Divergent functional profiles of acidic and basic phospholipases a2 in the venom of the snake porthidium lansbergii lansbergii. Toxicon 2016, 119, 289-298. [CrossRef] [PubMed]

87. Kini, R.M. Excitement ahead: Structure, function and mechanism of snake venom phospholipase a2 enzymes. Toxicon 2003, 42, 827-840. [CrossRef] [PubMed]

88. Nicolas, J.P.; Lin, Y.; Lambeau, G.; Ghomashchi, F.; Lazdunski, M.; Gelb, M.H. Localization of structural elements of bee venom phospholipase a2 involved in n-type receptor binding and neurotoxicity. J. Biol. Chem. 1997, 272, 7173-7181. [CrossRef]

89. Arita, H.; Hanasaki, K.; Nakano, T.; Oka, S.; Teraoka, H.; Matsumoto, K. Novel proliferative effect of phospholipase a2 in swiss 3t3 cells via specific binding site. J. Biol. Chem. 1991, 266, 19139-19141. [PubMed]

90. Fry, M.R.; Ghosh, S.S.; East, J.M.; Franson, R.C. Role of human sperm phospholipase a2 in fertilization: Effects of a novel inhibitor of phospholipase a2 activity on membrane perturbations and oocyte penetration. Biol. Reprod. 1992, 47, 751-759. [CrossRef]

91. Nakajima, M.; Hanasaki, K.; Ueda, M.; Arita, H. Effect of pancreatic type phospholipase a2 on isolated porcine cerebral arteries via its specific binding sites. Febs Lett. 1992, 309, 261-264. [CrossRef]

92. Malih, I.; Ahmad, R.M.R.; Tee, T.Y.; Saile, R.; Ghalim, N.; Othman, I. Proteomic analysis of moroccan cobra naja haje legionis venom using tandem mass spectrometry. J. Proteom. 2014, 96, 240-252. [CrossRef] 
93. Yap, M.K.; Fung, S.Y.; Tan, K.Y.; Tan, N.H. Proteomic characterization of venom of the medically important southeast asian naja sumatrana (equatorial spitting cobra). Acta Trop. 2014, 133, 15-25. [CrossRef]

94. Huang, H.W.; Liu, B.S.; Chien, K.Y.; Chiang, L.C.; Huang, S.Y.; Sung, W.C.; Wu, W.G. Cobra venom proteome and glycome determined from individual snakes of naja atra reveal medically important dynamic range and systematic geographic variation. J. Proteom. 2015, 128, 92-104. [CrossRef]

95. Shan, L.L.; Gao, J.F.; Zhang, Y.X.; Shen, S.S.; He, Y.; Wang, J.; Ma, X.M.; Ji, X. Proteomic characterization and comparison of venoms from two elapid snakes (bungarus multicinctus and naja atra) from china. J. Proteom. 2016, 138, 83-94. [CrossRef]

96. Sintiprungrat, K.; Watcharatanyatip, K.; Senevirathne, W.D.; Chaisuriya, P.; Chokchaichamnankit, D.; Srisomsap, C.; Ratanabanangkoon, K. A comparative study of venomics of naja naja from india and sri lanka, clinical manifestations and antivenomics of an indian polyspecific antivenom. J. Proteom. 2016, 132, 131-143. [CrossRef] [PubMed]

97. Choudhury, M.; McCleary, R.J.R.; Kesherwani, M.; Kini, R.M.; Velmurugan, D. Comparison of proteomic profiles of the venoms of two of the 'big four' snakes of india, the indian cobra (naja naja) and the common krait (bungarus caeruleus), and analyses of their toxins. Toxicon 2017, 135, 33-42. [CrossRef] [PubMed]

98. Lauridsen, L.P.; Laustsen, A.H.; Lomonte, B.; Gutierrez, J.M. Exploring the venom of the forest cobra snake: Toxicovenomics and antivenom profiling of naja melanoleuca. J. Proteom. 2017, 150, 98-108. [CrossRef] [PubMed]

99. Hus, K.K.; Buczkowicz, J.; Petrilla, V.; Petrillova, M.; Lyskowski, A.; Legath, J.; Bocian, A. First look at the venom of naja ashei. Molecules 2018, 23, 609. [CrossRef] [PubMed]

100. Silva-de-Franca, F.; Villas-Boas, I.M.; Serrano, S.M.T.; Cogliati, B.; Chudzinski, S.A.A.; Lopes, P.H.; Kitano, E.S.; Okamoto, C.K.; Tambourgi, D.V. Naja annulifera snake: New insights into the venom components and pathogenesis of envenomation. PLoS Negl. Trop. Dis. 2019, 13, e0007017. [CrossRef] [PubMed]

101. Gutierrez, J.M.; Rucavado, A. Snake venom metalloproteinases: Their role in the pathogenesis of local tissue damage. Biochimie 2000, 82, 841-850. [CrossRef]

102. Takeda, S.; Takeya, H.; Iwanaga, S. Snake venom metalloproteinases: Structure, function and relevance to the mammalian adam/adamts family proteins. Biochim. Biophys. Acta 2012, 1824, 164-176. [CrossRef] [PubMed]

103. Markland, F.S., Jr.; Swenson, S. Snake venom metalloproteinases. Toxicon 2013, 62, 3-18. [CrossRef]

104. Gutierrez, J.M.; Escalante, T.; Rucavado, A.; Herrera, C. Hemorrhage caused by snake venom metalloproteinases: A journey of discovery and understanding. Toxins 2016, 8, 93. [CrossRef]

105. Bernardoni, J.L.; Sousa, L.F.; Wermelinger, L.S.; Lopes, A.S.; Prezoto, B.C.; Serrano, S.M.; Zingali, R.B.; Moura-da-Silva, A.M. Functional variability of snake venom metalloproteinases: Adaptive advantages in targeting different prey and implications for human envenomation. PLoS ONE 2014, 9, e109651. [CrossRef]

106. Gutierrez, J.M.; Escalante, T.; Rucavado, A. Experimental pathophysiology of systemic alterations induced by bothrops asper snake venom. Toxicon 2009, 54, 976-987. [CrossRef]

107. Razi, M.T.; Asad, M.H.; Khan, T.; Chaudhary, M.Z.; Ansari, M.T.; Arshad, M.A.; Saqib, Q.N. Antihaemorrhagic potentials of fagonia cretica against naja naja karachiensis (black pakistan cobra) venom. Nat. Prod. Res. 2011, 25, 1902-1907. [CrossRef] [PubMed]

108. Costal-Oliveira, F.; Stransky, S.; Guerra-Duarte, C.; Naves de Souza, D.L.; Vivas-Ruiz, D.E.; Yarleque, A.; Sanchez, E.F.; Chavez-Olortegui, C.; Braga, V.M.M. L-amino acid oxidase from bothrops atrox snake venom triggers autophagy, apoptosis and necrosis in normal human keratinocytes. Sci. Rep. 2019, 9, 781. [CrossRef]

109. Fox, J.W. A brief review of the scientific history of several lesser-known snake venom proteins: L-amino acid oxidases, hyaluronidases and phosphodiesterases. Toxicon 2013, 62, 75-82. [CrossRef] [PubMed]

110. Izidoro, L.F.; Sobrinho, J.C.; Mendes, M.M.; Costa, T.R.; Grabner, A.N.; Rodrigues, V.M.; da Silva, S.L.; Zanchi, F.B.; Zuliani, J.P.; Fernandes, C.F.; et al. Snake venom l-amino acid oxidases: Trends in pharmacology and biochemistry. BioMed Res. Int. 2014, 2014, 196754. [CrossRef]

111. Costa, T.R.; Burin, S.M.; Menaldo, D.L.; de Castro, F.A.; Sampaio, S.V. Snake venom l-amino acid oxidases: An overview on their antitumor effects. J. Venom. Anim. Toxins Incl. Trop. Dis. 2014, 20, 23. [CrossRef] [PubMed]

112. Suhr, S.M.; Kim, D.S. Identification of the snake venom substance that induces apoptosis. Biochem. Biophys. Res. Commun. 1996, 224, 134-139. [CrossRef] [PubMed] 
113. Ande, S.R.; Kommoju, P.R.; Draxl, S.; Murkovic, M.; Macheroux, P.; Ghisla, S.; Ferrando-May, E. Mechanisms of cell death induction by l-amino acid oxidase, a major component of ophidian venom. Apoptosis 2006, 11, 1439-1451. [CrossRef] [PubMed]

114. Vogel, C.W.; Muller-Eberhard, H.J. Cobra venom factor: Improved method for purification and biochemical characterization. J. Immunol. Methods 1984, 73, 203-220. [CrossRef]

115. Laursen, N.S.; Andersen, K.R.; Braren, I.; Spillner, E.; Sottrup-Jensen, L.; Andersen, G.R. Substrate recognition by complement convertases revealed in the c5-cobra venom factor complex. Embo J. 2011, 30, 606-616. [CrossRef]

116. Vogel, C.W.; Fritzinger, D.C. Cobra venom factor: Structure, function, and humanization for therapeutic complement depletion. Toxicon 2010, 56, 1198-1222. [CrossRef]

117. Morgan, B.P.; Harris, C.L. Complement therapeutics; history and current progress. Mol. Immunol. 2003, 40, 159-170. [CrossRef]

118. Wang, B.; Xu, H.; Li, J.; Gao, H.M.; Xing, Y.H.; Lin, Z.; Li, H.J.; Wang, Y.Q.; Cao, S.H. Complement depletion with cobra venom factor alleviates acute hepatic injury induced by ischemiareperfusion. Mol. Med. Rep. 2018, 18, 4523-4529. [PubMed]

119. Wang, Y.L.; Kuo, J.H.; Lee, S.C.; Liu, J.S.; Hsieh, Y.C.; Shih, Y.T.; Chen, C.J.; Chiu, J.J.; Wu, W.G. Cobra crisp functions as an inflammatory modulator via a novel zn2+-and heparan sulfate-dependent transcriptional regulation of endothelial cell adhesion molecules. J. Biol. Chem. 2010, 285, 37872-37883. [CrossRef]

120. Chang, L.S.; Liou, J.C.; Lin, S.R.; Cheng, Y.C. Purification and characterization of taiwan cobra venom proteins with weak toxicity. Toxicon 2005, 45, 21-25. [CrossRef]

121. Wang, J.; Shen, B.; Guo, M.; Lou, X.; Duan, Y.; Cheng, X.P.; Teng, M.; Niu, L.; Liu, Q.; Huang, Q.; et al. Blocking effect and crystal structure of natrin toxin, a cysteine-rich secretory protein from naja atra venom that targets the bkca channel. Biochemistry 2005, 44, 10145-10152. [CrossRef]

122. Wang, F.; Li, H.; Liu, M.N.; Song, H.; Han, H.M.; Wang, Q.L.; Yin, C.C.; Zhou, Y.C.; Qi, Z.; Shu, Y.Y.; et al. Structural and functional analysis of natrin, a venom protein that targets various ion channels. Biochem. Biophys. Res. Commun. 2006, 351, 443-448. [CrossRef]

123. Zhou, Q.; Wang, Q.L.; Meng, X.; Shu, Y.; Jiang, T.; Wagenknecht, T.; Yin, C.C.; Sui, S.F.; Liu, Z. Structural and functional characterization of ryanodine receptor-natrin toxin interaction. Biophys. J. 2008, 95, 4289-4299. [CrossRef]

124. Osipov, A.V.; Levashov, M.Y.; Tsetlin, V.I.; Utkin, Y.N. Cobra venom contains a pool of cysteine-rich secretory proteins. Biochem. Biophys. Res. Commun. 2005, 328, 177-182. [CrossRef]

125. Serrano, S.M. The long road of research on snake venom serine proteinases. Toxicon 2013, 62, 19-26. [CrossRef]

126. Kang, T.S.; Georgieva, D.; Genov, N.; Murakami, M.T.; Sinha, M.; Kumar, R.P.; Kaur, P.; Kumar, S.; Dey, S.; Sharma, S.; et al. Enzymatic toxins from snake venom: Structural characterization and mechanism of catalysis. Febs J. 2011, 278, 4544-4576. [CrossRef]

127. Katzir, I.; Shani, J.; Goshen, G.; Sela, J.; Ninary, E.; Dogonovski, A.M.; Shabashov, D.; Inoue, S.; Ikeda, K.; Hayashi, K.; et al. Characterization of nerve growth factors (ngfs) from snake venoms by use of a novel, quantitative bioassay utilizing pheochromocytoma (pc12) cells overexpressing human trka receptors. Toxicon 2003, 42, 481-490. [CrossRef]

128. Kostiza, T.; Meier, J. Nerve growth factors from snake venoms: Chemical properties, mode of action and biological significance. Toxicon 1996, 34, 787-806. [CrossRef]

129. McCleary, R.J.; Kini, R.M. Non-enzymatic proteins from snake venoms: A gold mine of pharmacological tools and drug leads. Toxicon 2013, 62, 56-74. [CrossRef]

130. Uzair, B.; Khan, B.A.; Sharif, N.; Shabbir, F.; Menaa, F. Phosphodiesterases (pdes) from snake venoms: Therapeutic applications. Protein Pept. Lett. 2018, 25, 612-618. [CrossRef]

131. Thirawatananond, P.; McPherson, R.L.; Malhi, J.; Nathan, S.; Lambrecht, M.J.; Brichacek, M.; Hergenrother, P.J.; Leung, A.K.L.; Gabelli, S.B. Structural analyses of nudt16-adp-ribose complexes direct rational design of mutants with improved processing of poly(adp-ribosyl)ated proteins. Sci. Rep. 2019, 9, 5940. [CrossRef]

132. Yin, J.; Chen, S.; Zhang, N.; Wang, H. Multienzyme cascade bioreactor for a 10 min digestion of genomic DNA into single nucleosides and quantitative detection of structural DNA modifications in cellular genomic DNA. Acs. Appl. Mater. Interfaces 2018, 10, 21883-21890. [CrossRef]

133. Lai, W.; Lyu, C.; Wang, H. Vertical ultrafiltration-facilitated DNA digestion for rapid and sensitive uhplc-ms/ms detection of DNA modifications. Anal. Chem. 2018, 90, 6859-6866. [CrossRef] 
134. Willmann, L.; Erbes, T.; Krieger, S.; Trafkowski, J.; Rodamer, M.; Kammerer, B. Metabolome analysis via comprehensive two-dimensional liquid chromatography: Identification of modified nucleosides from rna metabolism. Anal. Bioanal. Chem. 2015, 407, 3555-3566. [CrossRef]

135. Carregari, V.C.; Rosa-Fernandes, L.; Baldasso, P.; Bydlowski, S.P.; Marangoni, S.; Larsen, M.R.; Palmisano, G. Snake venom extracellular vesicles (svevs) reveal wide molecular and functional proteome diversity. Sci. Rep. 2018, 8, 12067. [CrossRef]

136. Ogawa, Y.; Kanai-Azuma, M.; Akimoto, Y.; Kawakami, H.; Yanoshita, R. Exosome-like vesicles in gloydius blomhoffii blomhoffii venom. Toxicon 2008, 51, 984-993. [CrossRef]

137. Xu, R.; Greening, D.W.; Zhu, H.J.; Takahashi, N.; Simpson, R.J. Extracellular vesicle isolation and characterization: Toward clinical application. J. Clin. Investig. 2016, 126, 1152-1162. [CrossRef]

138. Yanez-Mo, M.; Siljander, P.R.; Andreu, Z.; Zavec, A.B.; Borras, F.E.; Buzas, E.I.; Buzas, K.; Casal, E.; Cappello, F.; Carvalho, J.; et al. Biological properties of extracellular vesicles and their physiological functions. J. Extracell. Vesicles 2015, 4, 27066. [CrossRef]

139. Raposo, G.; Stahl, P.D. Extracellular vesicles: A new communication paradigm? Nat. Rev. Mol. Cell Biol. 2019, 20, 509-510. [CrossRef]

140. Maas, S.L.N.; Breakefield, X.O.; Weaver, A.M. Extracellular vesicles: Unique intercellular delivery vehicles. Trends Cell Biol. 2017, 27, 172-188. [CrossRef]

141. Osier, N.; Motamedi, V.; Edwards, K.; Puccio, A.; Diaz-Arrastia, R.; Kenney, K.; Gill, J. Exosomes in acquired neurological disorders: New insights into pathophysiology and treatment. Mol. Neurobiol. 2018, 55, 9280-9293. [CrossRef]

142. Chong, S.Y.; Lee, C.K.; Huang, C.; Ou, Y.H.; Charles, C.J.; Richards, A.M.; Neupane, Y.R.; Pavon, M.V.; Zharkova, O.; Pastorin, G.; et al. Extracellular vesicles in cardiovascular diseases: Alternative biomarker sources, therapeutic agents, and drug delivery carriers. Int. J. Mol. Sci. 2019, 20, 3272. [CrossRef]

143. Klein-Scory, S.; Tehrani, M.M.; Eilert-Micus, C.; Adamczyk, K.A.; Wojtalewicz, N.; Schnolzer, M.; Hahn, S.A.; Schmiegel, W.; Schwarte-Waldhoff, I. New insights in the composition of extracellular vesicles from pancreatic cancer cells: Implications for biomarkers and functions. Proteome Sci. 2014, 12, 50. [CrossRef] [PubMed]

144. Luhtala, N.; Aslanian, A.; Yates, J.R., 3rd; Hunter, T. Secreted glioblastoma nanovesicles contain intracellular signaling proteins and active ras incorporated in a farnesylation-dependent manner. J. Biol. Chem. 2017, 292, 611-628. [CrossRef]

145. Cufaro, M.C.; Pieragostino, D.; Lanuti, P.; Rossi, C.; Cicalini, I.; Federici, L.; De Laurenzi, V.; Del Boccio, P. Extracellular vesicles and their potential use in monitoring cancer progression and therapy: The contribution of proteomics. J. Oncol. 2019, 2019, 1639854. [CrossRef]

146. Kriebel, P.W.; Majumdar, R.; Jenkins, L.M.; Senoo, H.; Wang, W.; Ammu, S.; Chen, S.; Narayan, K.; Iijima, M.; Parent, C.A. Extracellular vesicles direct migration by synthesizing and releasing chemotactic signals. J. Cell Biol. 2018, 217, 2891-2910. [CrossRef] [PubMed]

147. Meldolesi, J. Exosomes and ectosomes in intercellular communication. Curr. Biol. 2018, 28, R435-R444. [CrossRef] [PubMed]

148. Willms, E.; Cabanas, C.; Mager, I.; Wood, M.J.A.; Vader, P. Extracellular vesicle heterogeneity: Subpopulations, isolation techniques, and diverse functions in cancer progression. Front. Immunol. 2018, 9, 738. [CrossRef] [PubMed]

149. Olamendi-Portugal, T.; Batista, C.V.F.; Pedraza-Escalona, M.; Restano-Cassulini, R.; Zamudio, F.Z.; Benard-Valle, M.; de Roodt, A.R.; Possani, L.D. New insights into the proteomic characterization of the coral snake micrurus pyrrhocryptus venom. Toxicon 2018, 153, 23-31. [CrossRef]

150. Wolfenden, R.N. On the nature and action of the venom of poisonous snakes: Ii. A note upon the venom of the indian viper (daboia russellii). J. Physiol. 1886, 7, 357-364. [CrossRef]

151. Shao, J.; Shen, H.; Havsteen, B. Purification, characterization and binding interactions of the chinese-cobra (naja naja atra) serum antitoxic protein csap. Biochem J. 1993, 293, 559-566. [CrossRef]

152. Wang, X.; Buck, F.; Havsteen, B. Elucidation of a new biological function of an old protein: Unique structure of the cobra serum albumin controls its specific toxin binding activity. Int. J. Biochem. Cell Biol. 1998, 30, 225-233. [CrossRef]

153. Ohkura, N.; Inoue, S.; Ikeda, K.; Hayashi, K. The two subunits of a phospholipase a2 inhibitor from the plasma of thailand cobra having structural similarity to urokinase-type plasminogen activator receptor and ly-6 related proteins. Biochem. Biophys Res. Commun 1994, 204, 1212-1218. [CrossRef] 
154. Okumura, K.; Masui, K.; Inoue, S.; Ikeda, K.; Hayashi, K. Purification, characterization and cdna cloning of a phospholipase a2 inhibitor from the serum of the non-venomous snake elaphe quadrivirgata. Biochem. J. 1999, 341, 165-171. [CrossRef]

155. Ullah, A.; Masood, R. The sequence and three-dimensional structure characterization of snake venom phospholipases b. Front. Mol. Biosci. 2020, 7, 175. [CrossRef]

156. Georgieva, D.; Seifert, J.; Ohler, M.; von Bergen, M.; Spencer, P.; Arni, R.K.; Genov, N.; Betzel, C. Pseudechis australis venomics: Adaptation for a defense against microbial pathogens and recruitment of body transferrin. J. Proteome Res. 2011, 10, 2440-2464. [CrossRef]

157. Takahashi, H.; Hattori, S.; Iwamatsu, A.; Takizawa, H.; Shibuya, M. A novel snake venom vascular endothelial growth factor (vegf) predominantly induces vascular permeability through preferential signaling via vegf receptor-1. J. Biol. Chem. 2004, 279, 46304-46314. [CrossRef]

158. Yamazaki, Y.; Matsunaga, Y.; Tokunaga, Y.; Obayashi, S.; Saito, M.; Morita, T. Snake venom vascular endothelial growth factors (vegf-fs) exclusively vary their structures and functions among species. J. Biol. Chem. 2009, 284, 9885-9891. [CrossRef]

159. Toivanen, P.I.; Nieminen, T.; Laakkonen, J.P.; Heikura, T.; Kaikkonen, M.U.; Yla-Herttuala, S. Snake venom vegf vammin induces a highly efficient angiogenic response in skeletal muscle via vegfr-2/nrp specific signaling. Sci. Rep. 2017, 7, 5525. [CrossRef] [PubMed]

160. Norton, R.S.; Chandy, K.G. Venom-derived peptide inhibitors of voltage-gated potassium channels. Neuropharmacology 2017, 127, 124-138. [CrossRef] [PubMed]

161. Yang, W.; Feng, J.; Wang, B.; Cao, Z.; Li, W.; Wu, Y.; Chen, Z. Bf9, the first functionally characterized snake toxin peptide with kunitz-type protease and potassium channel inhibiting properties. J. Biochem. Mol. Toxicol. 2014, 28, 76-83. [CrossRef] [PubMed]

162. Pung, Y.F.; Wong, P.T.; Kumar, P.P.; Hodgson, W.C.; Kini, R.M. Ohanin, a novel protein from king cobra venom, induces hypolocomotion and hyperalgesia in mice. J. Biol. Chem. 2005, 280, 13137-13147. [CrossRef]

163. Aird, S.D. Ophidian envenomation strategies and the role of purines. Toxicon 2002, 40, 335-393. [CrossRef]

164. Dhananjaya, B.L.; D'Souza, C.J. The pharmacological role of nucleotidases in snake venoms. Cell Biochem. Funct. 2010, 28, 171-177. [CrossRef]

165. Vaiyapuri, S.; Wagstaff, S.C.; Watson, K.A.; Harrison, R.A.; Gibbins, J.M.; Hutchinson, E.G. Purification and functional characterisation of rhiminopeptidase a, a novel aminopeptidase from the venom of bitis gabonica rhinoceros. PLoS Negl. Trop. Dis. 2010, 4, e796. [CrossRef]

166. Brillard-Bourdet, M.; Nguyen, V.; Ferrer-di Martino, M.; Gauthier, F.; Moreau, T. Purification and characterization of a new cystatin inhibitor from taiwan cobra (naja naja atra) venom. Biochem. J. 1998, 331 Pt 1, 239-244. [CrossRef]

167. Fry, B.G.; Vidal, N.; Norman, J.A.; Vonk, F.J.; Scheib, H.; Ramjan, S.F.; Kuruppu, S.; Fung, K.; Hedges, S.B.; Richardson, M.K.; et al. Early evolution of the venom system in lizards and snakes. Nature 2006, 439, 584-588. [CrossRef] [PubMed]

168. Gutierrez, J.M.; Lomonte, B.; Leon, G.; Rucavado, A.; Chaves, F.; Angulo, Y. Trends in snakebite envenomation therapy: Scientific, technological and public health considerations. Curr. Pharm. Des. 2007, 13, 2935-2950. [CrossRef] [PubMed]

169. Zhao, H.; Gan, T.X.; Liu, X.D.; Jin, Y.; Lee, W.H.; Shen, J.H.; Zhang, Y. Identification and characterization of novel reptile cathelicidins from elapid snakes. Peptides 2008, 29, 1685-1691. [CrossRef] [PubMed]

170. Oh, J.H.; Hyun, J.Y.; Varshavsky, A. Control of hsp90 chaperone and its clients by n-terminal acetylation and the n-end rule pathway. Proc. Natl. Acad. Sci. USA 2017, 114, E4370-E4379. [CrossRef]

171. Shemorry, A.; Hwang, C.S.; Varshavsky, A. Control of protein quality and stoichiometries by n-terminal acetylation and the n-end rule pathway. Mol. Cell 2013, 50, 540-551. [CrossRef]

172. Drazic, A.; Myklebust, L.M.; Ree, R.; Arnesen, T. The world of protein acetylation. Biochim Biophys. Acta 2016, 1864, 1372-1401. [CrossRef]

173. Ree, R.; Varland, S.; Arnesen, T. Spotlight on protein n-terminal acetylation. Exp. Mol. Med. 2018, 50, 90. [CrossRef]

174. Ma, B. Novor: Real-time peptide de novo sequencing software. J. Am. Soc. Mass Spectrom 2015, 26, 1885-1894. [CrossRef] 
175. Muth, T.; Weilnbock, L.; Rapp, E.; Huber, C.G.; Martens, L.; Vaudel, M.; Barsnes, H. Denovogui: An open source graphical user interface for de novo sequencing of tandem mass spectra. J. Proteome Res. 2014, 13, 1143-1146. [CrossRef]

176. Perez-Riverol, Y.; Csordas, A.; Bai, J.; Bernal-Llinares, M.; Hewapathirana, S.; Kundu, D.J.; Inuganti, A.; Griss, J.; Mayer, G.; Eisenacher, M.; et al. The pride database and related tools and resources in 2019: Improving support for quantification data. Nucleic Acids Res. 2019, 47, D442-D450. [CrossRef] [PubMed]

Publisher's Note: MDPI stays neutral with regard to jurisdictional claims in published maps and institutional affiliations.

(C) 2020 by the authors. Licensee MDPI, Basel, Switzerland. This article is an open access article distributed under the terms and conditions of the Creative Commons Attribution (CC BY) license (http://creativecommons.org/licenses/by/4.0/). 